\title{
Human model of IRX5 mutations reveals key role for this transcription factor in ventricular conduction
}

Zeina R Al Sayed, $\mathrm{PhD}^{1}$, Robin Canac, $\mathrm{MSc}^{1}$, Bastien Cimarosti, $\mathrm{MSc}^{1}$, Carine Bonnard, $\mathrm{PhD}^{2}$, Jean-Baptiste Gourraud, MD-PhD ${ }^{1,12}$, Hanan Hamamy, $\mathrm{MD}^{3}$, Hulya Kayserili, MD-PhD ${ }^{4}$, Aurore Girardeau, BSc ${ }^{1}$, Mariam Jouni ${ }^{1}, \mathrm{PhD}$, Nicolas Jacob, $\mathrm{MD}^{1}$, Anne Gaignerie, MSc ${ }^{5}$, Caroline Chariau, $\mathrm{BSc}^{5}$, Laurent David, $\mathrm{PhD}^{5-7}$, Virginie Forest, $\mathrm{PhD}^{1}$, Céline Marionneau, $\mathrm{PhD}^{1}$, Flavien Charpentier, $\mathrm{PhD}^{1,12}$, Gildas Loussouarn, $\mathrm{PhD}^{1}$, Guillaume Lamirault, MD$\mathrm{PhD}^{1}$, Bruno Reversade, $\mathrm{PhD}^{2,4,8-10}$, Kazem Zibara, $\mathrm{PhD}^{11}$, Patricia Lemarchand, MD-PhD ${ }^{1,12^{*}}$, Nathalie Gaborit, $\mathrm{PhD}^{1 *}$

1. Université de Nantes, CNRS, INSERM, l'institut du thorax, F-44000 Nantes, France

2. Institute of Medical Biology, A*STAR, Singapore, Singapore.

3. Department of Genetic Medicine and Development, Geneva University, Geneva 1211, Switzerland.

4. Medical Genetics Department, Koç University School of Medicine (KUSOM), Istanbul, Turkey.

5. Université de Nantes, CHU Nantes, Inserm, CNRS, SFR Santé, Inserm UMS 016, CNRS UMS 3556, F-44000 Nantes, France

6. CRTI, INSERM, UNIV Nantes, Nantes, France.

7. ITUN, CHU Nantes, Nantes, France.

8. Department of Paediatrics, National, University of Singapore, Singapore, Singapore.

9. Institute of Molecular and Cellular Biology, A*STAR, Singapore, Singapore.

10. Reproductive Biology Laboratory, Amsterdam UMC, Amsterdam-Zuidoost, Netherlands. 11. ER045, Laboratory of stem cells, DSST, Biology department, Faculty of Sciences, Lebanese University, Beirut, Lebanon.

12. Université de Nantes, CHU Nantes, CNRS, INSERM, l'institut du thorax, F-44000 Nantes, France.

* co-corresponding authors

Short title: Key role of IRX5 in human ventricular conduction

Total word count: 9911

Manuscript category: Original article

Reprint requests and correspondence:

Nathalie GABORIT, PhD and Patricia Lemarchand, MD-PhD

l'institut du thorax

Inserm UMR 1087, CNRS UMR 6291

IRS-UN, 8 quai Moncousu

44007 Nantes cedex 1, France

E-mail: nathalie.gaborit@univ-nantes.fr and patricia.lemarchand@univ-nantes.fr 


\section{Abstract}

Aim: Several inherited arrhythmic diseases have been linked to single gene mutations in cardiac ion channels and interacting proteins. However, the mechanisms underlying most arrhythmias, are thought to involve altered regulation of the expression of multiple effectors. In this study, we aimed to examine the role of a transcription factor belonging to the Iroquois homeobox family, IRX5, in cardiac electrical function.

Methods and results: Using human cardiac tissues, transcriptomic correlative analyses between IRX5 and genes involved in cardiac electrical activity showed that in human ventricular compartment, IRX5 expression strongly correlated to the expression of major actors of cardiac conduction, including the sodium channel, Nav1.5, and Connexin 40 (Cx40). We then generated human induced pluripotent stem cells (hiPSCs) derived from two Hamamy Syndrome-affected patients carrying distinct homozygous loss-of-function mutations in IRX5 gene. Cardiomyocytes derived from these hiPSCs showed impaired cardiac gene expression program, including misregulation in the control of Nav1.5 and Cx40 expression. In accordance with the prolonged QRS interval observed in Hamamy Syndrome patients, a slower ventricular action potential depolarization due to sodium current reduction was observed on electrophysiological analyses performed on patient-derived cardiomyocytes, confirming the functional role of IRX5 in electrical conduction. Finally, a novel cardiac transcription factor complex was identified, composed by IRX5 and GATA4, in which IRX5 potentiated GATA4induction of SCN5A expression.

Conclusions: Altogether, this work unveils a key role for IRX5 in the regulation of human ventricular depolarization and cardiac electrical conduction, providing therefore new insights into our understanding of cardiac diseases.

\section{Keywords:}

IRX5, transcription factors, conduction, arrhythmia, Hamamy syndrome, human induced pluripotent stem cells. 
CVR-2019-1019R2

\section{Translational perspectives}

Inherited cardiac arrhythmias account for about $20 \%$ of sudden cardiac deaths, of which a small portion are monogenic familial diseases with mutations in cardiac ion channels. However, pathogeny of inherited cardiac arrhythmias is increasingly thought to result from complex mechanisms involving altered regulation of multiple effectors expression. Taking advantage of cardiomyocytes derived from Hamamy syndrome patients, carrying loss-of-function mutations in IRX5 transcription factor, we uncovered an important role for IRX5 in the regulation of several major players of ventricular depolarization conduction and in arrhythmogenesis. Thus, this study supports systematic screening for genetic variants in IRX5 in inherited cardiac arrhythmias. 
CVR-2019-1019R2

\section{Introduction}

Inherited cardiac arrhythmias account for about $20 \%$ of sudden cardiac deaths. Only a small portion of these arrhythmias are monogenic familial diseases, having been successfully linked to rare mutations in cardiac ion channels and related proteins [1]. However, pathogeny of inherited cardiac arrhythmias is increasingly thought to be based on complex mechanisms involving polygenic inheritance and/or altered regulation of the expression of multiple effectors [2]. In this context, investigating how dysfunction of transcriptional regulators participates in the mechanism of these diseases is of major importance.

The regulation of global cardiac electrical transcriptional program, including ion channels and gap junctions, is a major determinant of proper initiation and propagation of action potential (AP) through the cardiac muscle. In animal models, several transcription factors (TFs) are implicated in cardiac electrical activity and arrhythmias [3], including members of the Iroquois (IRX) family of TFs [4].

Autosomal recessive mutations in IRX5, an Iroquois homeobox TF, is linked to Hamamy Syndrome (HMMS, OMIM611174), an inherited congenital disorder. The patients' cardiac clinical phenotype combines bradycardia and QRS complex prolongation, illustrating a delayed ventricular electrical conduction [5,6]. Surprisingly, in mice, deletion of Irx 5 leads to a different phenotype, a ventricular repolarization defect, due to the role of Irx 5 in controlling potassium channel gene expression [7]. Inversely, another murine member of the Irx family, Irx3, is essential for fine regulation of intercellular coupling within the ventricular conduction system, through the regulation of connexins expression [8,9]. This suggests that distinct regulatory pathways govern the differences between human and animal cardiac electrical physiology.

In this study, our goal was to decipher whether IRX5 controls human cardiac electrical activity. First, correlative transcriptomic analyses between IRX5 and cardiac electrophysiology genes in human cardiac tissues, suggested that IRX5 may regulate several major actors of cardiac conduction. Then, human induced pluripotent stem cells (hiPSCs) derived from HMMS patients carrying IRX5 mutations were used to elucidate the role of IRX5 in regulating expression of these actors of cardiac conduction and to uncover a cooperative activity between TFs. This work reveals how LOF mutation in one key TF affects the expression of multiple effectors of ventricular electrical conduction and improves our understanding of cardiac disease, paving the way therefore for more effective therapies. 


\section{Methods}

\section{Ethical Statement:}

The study was conducted according to the principles set forth under the Declaration of Helsinki (1989) and European guidelines for clinical and genetic research. Institutional review board approvals of the study were obtained before the initiation of patient enrollment. Regarding the patient-derived biological samples, signed informed consent allowing the experiments to be conducted have been received from all individuals. Any related health information was collected in compliance with applicable law/regulation and with any applicable policy of the ethics committee with jurisdiction over the biological sample collection. All biological samples and their related health information have been provided in coded form such that subjects cannot be identified directly. The provisions of French law, article L1110-4 of the Code de la santé publique, related to the privacy and confidentiality of information regarding patients, have been observed. The transfer of the Hamamy syndrome-affected (HMMS) patient's biological samples has complied with all applicable laws as well as legal, regulatory and ethical requirements in transferring and obtaining such Material and the corresponding informed consents (Authorization IE 2009-505(1)).

\subsection{Transcriptional analysis of human and murine tissues}

RNA sequencing data in human heart were collected from the GTEx portal website (http://gtexportal.org). Briefly, transcripts per million (TPM) were downloaded for 297 atrial and 303 ventricular available tissue samples.

Regarding murine samples, all animal experiments obtained local approval and all animal procedures follow the guidelines from Directive 2010/63/EU of the European Parliament on the protection of animals used for scientific purposes. Mice were euthanized in their home cage using CO2 inhalation. Hearts were excised from six 10-week-old C57BL/6 male mice and atria and ventricles were carefully dissected as previously described [10].

Two-way hierarchical agglomerative clustering was applied to gene-expression matrices (see TLDA section below), by centering gene expression values on the values-median and using average linkage-clustering with uncentered correlation (Cluster 3.0). GTEx left ventricular tissues RNA sequencing data of cardiac sodium channels and connexins were ranked according to ascending expression of IRX5. Genes encoding sodium channel subunits and connexins that presented a median GTEx expression level in left ventricular samples higher than 1 TPM were selected. Expression correlations were tested using Pearson correlation package on R software. 


\subsection{Human induced pluripotent stem cells (hiPSC) generation}

Primary dermal fibroblasts were derived from skin biopsies obtained from donors of two different consanguineous families, previously described with Hamamy Syndrome $[5,6]$. The first diseased donor is a 4-year-old boy, homozygous carrier of the c.448G $>$ C IRX5 mutation (p.Ala150Pro annotated as A150P) in whom a QRS prolongation on the ECG was diagnosed. The second donor is a 17-year-old boy belonging to another family harboring the homozygous c.498C>A IRX5 mutation (p.Asn166Lys annotated as N166K) who presents a prolonged QRS duration on the ECG, in addition to a tiny patent ductus arteriosus. In parallel, fibroblasts from three individuals lacking the IRX5 mutations were used as controls: hiPS cells were generated from an intrafamilial control of the patient carrying the A150P-IRX5 mutation, his unaffected sister. hiPS cells were also generated from an extrafamilial control of the patient carrying the N166K-IRX5 mutation, who has been chosen because of its match in terms of age, sex and ethnicity to the patient. A third control hiPS cell line, which was not related to both HMMS patients, and that had previously been described, has been also used [11-13]. HiPSC lines were generated using Sendai virus method. For each line, two to three hiPSC clones were selected and expanded on stem cell-qualified Matrigel-coated plates $(0.1 \mathrm{mg} / \mathrm{ml}$; BD Bioscience) with StemMACS ${ }^{\mathrm{TM}}$ iPS Brew XF medium (Miltenyi Biotec).

\subsection{HiPSC characterization}

For all clones, genomic DNA was extracted and mutations were verified by sequencing using primers specific for the genomic regions surrounding the A150P and N166K mutations (Supplemental Table 1). Pluripotency marker gene expression was assessed using flow cytometry, qRT-PCR, and immunofluorescence as previously described [11]. Single nucleotide polymorphism (SNP) analysis of hiPSCs compared to their parental skin fibroblast cells was used to confirm genome integrity after reprogramming. DNA was extracted from somatic and hiPSC samples using the QIAGEN QiaAmp kit, according to the manufacturer's recommendations. The gDNA was quantified using a nanodrop. $200 \mathrm{ng}$ of gDNA was outsourced to Integragen Company (Evry, France) for karyotype analysis using HumanCore24-v1 SNP arrays. This array contains over 300,000 probes distributed throughout the genome with a median coverage of one probe every 5700 bases. All genomic positions were based on Human Genome Build 37 (hg19). Analysis was performed with GenomeStudio software. Chromosome abnormalities were determined by visual inspection of $\log \mathrm{R}$ ratios and $\mathrm{B}$-allele frequencies (BAF) values and comparing parental cells and hiPS-derived samples. LogR ratio, the ratio between observed and expected probe intensity, is informative of copy number 
variation (CNV, i.e., deletions/duplications), whereas BAF is informative of heterozygosity. SNP data were used to compute CNV. In particular, this type of chips allows detecting loss of heterozygosity $(\mathrm{LOH})$, an important concern for hiPSC, which is not detectable with classical CGH arrays.

\subsection{Differentiation of hiPSCs into cardiomyocytes (CMs)}

At $80 \%$ of cell confluency, hiPSC lines were passaged using Gentle Cell Dissociation Reagent (STEMCELL Technologies) and Y-27632 Rho-kinase inhibitor (STEMCELL Technologies). The matrix sandwich method was used to generate CMs, as previously described [12]. From day 5 of differentiation, cell medium was changed every other day with RPMI-1640 medium supplemented with B27 (with insulin; Thermo Fisher Scientific). After 20 to 28 days following the beginning of differentiation, spontaneously beating cell clusters were mechanically isolated using a needle and then used for electrophysiological, biochemical and molecular analyses. All experiments have been performed on at least 3 independent differentiations for each clone, performed on different hiPS cell passages. Data obtained from the various clones of the 3 control lines have been pooled and averaged and correspond to the $\mathrm{n}$ values provided in the figure legends. For each Hamamy patient, data obtained from the different clones have been pooled and averaged.

\subsection{RNA expression}

RNA extraction: Samples of total RNA were obtained using the NucleoSpin RNA kit (MACHEREY-NAGEL) following the manufacturer's specifications.

TaqMan low-density array (TLDA) : TLDA studies were conducted using six ventricular and six atrial control murine tissues as well as beating clusters of hiPS-CMs obtained from 12 control and 9 IRX5-mutant CM differentiations. $1 \mu \mathrm{g}$ of RNA was reverse transcribed into cDNA using SuperScript IV Vilo Master Mix (Thermo Fisher Scientific). For murine tissues, three specifically designed 384-well TLDA were used: one containing 4x 96 primers and probes for cardiac ion channels [10] and 2 others, each containing a set of 4x 96 primers and probes for cardiac transcription factors (Supplemental Table 2A). For hiPS-CMs, TLDA probe selection covered gene families implicated in cardiac ion channel expression and regulation, and cardiomyocyte structure (Supplemental Table 2B). Genes with average $\mathrm{Ct}>32$ in all compared groups were considered undetectable and excluded from the analysis (SCN10A and $\mathrm{ABCC} 8$ ). Average $\mathrm{Ct}$ of remaining genes for each sample was used for data normalization [1416]. 
3' Sequencing RNA Profiling (3'SRP): 3'SRP protocol was performed according to Kilens et al [17]. Briefly, the libraries were prepared from $10 \mathrm{ng}$ of total RNA. 40 RNA samples were extracted from 8 IRX5-mutated and 13 control hiPSC samples (a duplicate for each clone obtained at different cell passages) and 19 samples of corresponding hiPS-CMs. The mRNA poly(A) tail was tagged with universal adapters, well-specific barcodes and unique molecular identifiers (UMIs) during template-switching reverse transcriptase. Barcoded cDNAs from multiple samples were then pooled, amplified and tagmented using a transposon-fragmentation approach which enriches for 3'ends of cDNA. A library of 350-800bp was run on an Illumina HiSeq 2500 using a HiSeq Rapid SBS Kit v2 (50 cycles; FC-402-4022) and a HiSeq Rapid PE Cluster Kit v2 (PE-402-4002). Read pairs used for analysis matched the following criteria: all sixteen bases of the first read had quality scores of at least 10 and the first six bases correspond exactly to a designed well-specific barcode. The second reads were aligned to RefSeq human mRNA sequences (hg19) using bwa version 0.7.4 4. Reads mapping to several positions into the genome were filtered out from the analysis. Digital gene expression profiles were generated by counting the number of unique UMIs associated with each RefSeq genes, for each sample. R package DESeq2 was used to normalize gene expression. Differentially expressed genes were finally clustered using cluster 3.0 software. Enriched biological pathways were assigned for differentially expressed genes in IRX5-mutated vs. control hiPS-CMs. For that, Reactome pathways were attributed to the most variant genes with p-value $<0.05[18,19]$. However, genes encoding for ion channels exhibited low expression levels and therefore they were not taken into consideration for differentially expressed genes analysis. To overcome this issue, $p$-values for these genes were calculated based on TLDA analysis. Babelomics was then used to calculate enrichment of Reactome pathways for genes differentially expressed in both TLDA and 3'SRP analyses. Finally, enrichment scores (ES) were calculated [20,21].

\subsection{Protein expression and interaction}

Protein extraction: IRX5, Nav1.5, Cx40 and GATA4 expression were evaluated in human left and right ventricular tissues obtained from three non-diseased individuals as previously described [22]. Corresponding subendocardial (also containing Purkinje cells) and subepicardial tissue slices were obtained at the cardiac base and snap-frozen in liquid nitrogen. Protein expressions and interactions were also investigated in beating hiPS-CMs at day 28 of differentiation. For protein extraction, cells were homogenized on ice using lysis buffer containing in mM: $1 \%$ TritonX-100; $100 \mathrm{NaCl} ; 50$ Tris-HCl; 1 EGTA; $1 \mathrm{Na}_{3} \mathrm{VO}_{4} ; 50 \mathrm{NaF} ; 1$ phenylmethylsulfonyl fluoride and protease inhibitors cocktail (P8340, Sigma-Aldrich). 
Extracted samples were sonicated and centrifuged at $15,000 \times \mathrm{g}$ for $15 \mathrm{~min}$ at $4^{\circ} \mathrm{C}$. Protein quantification was carried out using Pierce ${ }^{\mathrm{TM}}$ BCA Protein Assay Kit (Thermo Fisher). Immunoblot was finally done using the corresponding primary antibodies (Supplemental Table $3)$.

Subcellular protein fractionation: To unveil the impact of IRX5 mutations on its cellular localization, nuclear and cytosolic proteins were separated. For that, cytoplasmic membranes were disrupted on ice in a hypotonic solution including in mM: $500 \mathrm{HEPES}, 500 \mathrm{MgCl}_{2}, 500$ $\mathrm{KCl}, 0.1 \mathrm{DTT}$ and protease inhibitor cocktail. Cells nuclei were pelleted by $2000 \mathrm{rpm}$ centrifugation and the supernatant contained the cytosolic fraction. In order to extract nuclear proteins, a protein extraction buffer was added to pellets followed by sonication.

Co-immunoprecipitation: This was performed to investigate protein-to-protein interactions between IRX5 and GATA4 in hiPS-CMs. A total of $12.5 \mu 1$ magnetic Dynabeads ${ }^{\circledR}$ Protein G (Thermo Fisher Scientific) were added to $3 \mu \mathrm{g}$ anti-IRX5 antibody (WH0010265M1, SigmaAldrich) or anti-mouse IgG antibody as control (02-6502, Thermo Fisher Scientific) and conjugated by incubation for $40 \mathrm{~min}$ at room temperature with rotation. The complex beadsantibody was cross-linked using $27 \mathrm{mg}$ DMP (dimethyl pimelimidate, Thermo Fisher Scientific), and then incubated for 2 hours with $800 \mu \mathrm{g}$ of total lysate at $4^{\circ} \mathrm{C}$. The supernatant was then discarded and the beads were washed with the lysis buffer. Proteins were eluted in 30 $\mu 1$ of a mixture of NuPAGE® Sample Reducing Agent (10X) and LDS Sample Buffer (4X) (Invitrogen) and heated at $60^{\circ} \mathrm{C}$. The samples were then loaded onto a $4-15 \%$ precast polyacrylamide gel (Bio-Rad).

\subsection{Immunofluorescence}

HiPSCs or hiPS-CMs at day 20 of differentiation were dissociated using collagenase II (Gibco) and seeded onto 8-wells iBidi plates (Biovalley) coated with Matrigel (Corning). Twelve days later, cultured cells were immunostained using a staining buffer set according to the manufacturer's instructions (00-5523-00, Thermo Fisher Scientific). HiPS-CMs were labeled by cardiac differentiation markers or transcription factor. Primary antibodies are listed in Supplemental Table 3. DNA was highlighted using DAPI and pictures were taken using confocal microscopy (Nikon; MicroPICell core facility).

\subsection{Chromatin immunoprecipitation (ChIP)}

IRX5 binding sites: Promoter DNA sequences were found using Ensembl. Consensus sequences known to mediate Iroquois transcription factor interaction with DNA [23-25] were 
screened on gene promoters. Each site was verified for its conservation among species using rVista 2.0. Primers surrounding the identified conserved potential binding sites (BS) were designed using Primer 3. Corresponding primer sequences are detailed in Supplemental Table 4.

ChIP: At day 28 of differentiation, beating cardiomyocyte clusters were isolated and crosslinked. After chromatin sonication, IRX5 antibody (WH0010265M1, Sigma-Aldrich) was added followed by the addition of protein G-coated dynabeads. Following overnight incubation, the chromatin was then eluted and reverse-crosslinked. SYBER green qRT-PCR method was finally performed using the designed primers (Supplemental Table 4) to test for enrichment of the targeted sequences. Results are shown as percentage of input.

To confirm the specificity of IRX5 antibody, HEK293 cells were transfected using plasmids encoding human sequences of WT IRX5, N166K IRX5, and WT IRX3, as well as an empty pcDNA3 plasmid. Testing the potential non specificity of IRX5 antibody towards IRX3 was performed as IRX3 and IRX5 have been shown to share a high level of transcript and protein homology [26], strong similarities in their expression pattern [27] and to have coordinated functional roles [28]. (1) Confirming the IRX3 protein expression in all cell samples transfected by IRX3, a band at the expected size for IRX3 (below 100kDa, as IRX3 was Myc-tagged) was indeed obtained (Figure S1). (2) When HEK293 cells were transfected by an empty plasmid or IRX3 plasmid, as expected, on corresponding western-blots with IRX5 antibody, no band was detected, demonstrating that IRX5 antibody did not bind other protein than IRX5, including IRX3. (3) Cells were transfected by IRX5 (left panel) or IRX5-N166K (right panel) plasmids and a unique band of the expected size for IRX5 (around $100 \mathrm{kDa}$, as IRX5 was GFP-tagged) was observed, further demonstrating that the antibody specifically bound to the WT or mutated forms of IRX5 protein (Figure S1).

\subsection{Cellular electrophysiology}

Cell dissociation: hiPS-CMS were enzymatically dissociated into single cells using collagenase II (Gibco) at $37^{\circ} \mathrm{C}$ for $20 \mathrm{~min}$. Cells were then incubated at RT for $30 \mathrm{~min}$ in KraftBruhe solution containing (in $\mathrm{mM}$ ): $85 \mathrm{KCl} ; 30 \mathrm{~K}_{2} \mathrm{HPO}_{4} ; 5 \mathrm{MgSO}_{4} ; 20$ glucose; 20 taurine; 5 Na pyruvate; 5 creatine; 2 K2-ATP; 1 EGTA; pH 7.2 adjusted with KOH. Single cells were then plated at low density on Matrigel-coated Petri-dishes (Nunc) and recorded 11 to 14 days after dissociation.

Data recording and analysis: Stimulation and data recording were performed at $37^{\circ} \mathrm{C}$ using an Axopatch 200B amplifier controlled by Axon pClamp 10.6 software through an A/D 
converter (Digidata 1440A) (all Molecular Devices). Data were analyzed using Clampfit 10.6 software. For all cell lines, data were collected from at least 3 independent differentiations. Experimental details regarding solutions composition are described in Supplemental Table 5.

Current clamp: Action potential (AP) recordings were obtained using the amphotericin-Bperforated patch-clamp technique. Patch pipettes were pulled from borosilicate glass capillaries (Sutter instruments) to obtain a tip resistance of 2 to $3 \mathrm{M} \Omega$. APs were recorded in cells that were first allowed to beat spontaneously and then paced. A stimulus of an amplitude of 30-35 $\mathrm{pA} / \mathrm{pF}$ during $1 \mathrm{~ms}$ (in order to avoid interference with the upstroke phase of the AP) was used at various frequencies, in absence of $\mathrm{I}_{\mathrm{K} 1}$ injection (see below). Cells were classified as either ventricular, atrial or nodal, based on several parameters previously described (maximum upstroke velocity, $\mathrm{dV} / \mathrm{dt}_{\max }$; action potential duration, APD; resting membrane potential, $\mathrm{RMP}$ ) [11]. Only ventricular cells were selected for further analysis. $\mathrm{I}_{\mathrm{K} 1}$ current was not observed in hiPS-CMs (not shown), consistent with the observation of phase-4 depolarization in these cells. Without $\mathrm{I}_{\mathrm{K} 1}$, the APs resting membrane potential (RMP) was about $-60 \mathrm{mV}$ (see Figure 5B), which corresponds to immature ventricular cardiomyocytes. Thus electronic expression of the inward rectifier potassium current, $\mathrm{I}_{\mathrm{K} 1}$, was realized using dynamic patch-clamp [29,30]. With $2 \mathrm{pA} / \mathrm{pF}$ of in silico $\mathrm{I}_{\mathrm{k} 1}$ injection, hiPS-CM membrane resting potential was about $-80 \mathrm{mV}$, closer to physiological RMP of adult ventricular cardiomyocytes. Averaged parameters were obtained from 7 consecutive APs. Both cell stimulation and injection of $\mathrm{I}_{\mathrm{k} 1}$ were realized by a custom-made software running on RT-Linux and a National Instrument A/D converter (NI PCI6221) connected to the current command of the amplifier.

Voltage clamp: $\mathrm{I}_{\mathrm{Na}}$ and $\mathrm{I}_{\mathrm{Ca}, \mathrm{L}}$ recordings were performed in the ruptured whole-cell configuration using voltage clamp protocol as depicted in the figures. Pipettes (Sutter instruments) with 1.7-2.5M $\Omega$ tip resistance were waxed before use to decrease pipette capacitive currents. $\mathrm{I}_{\mathrm{Ca}, \mathrm{L}}$, and $\mathrm{I}_{\mathrm{Na}}$ recordings were low-pass filtered at, respectively, $3 \mathrm{KHz}$ and $10 \mathrm{KHz}$. Holding potentials were respectively $-80 \mathrm{mV}$ and $-100 \mathrm{mV}$. The capacitance and series were compensated using a VE-2 amplifier (Alembic Instrument, Qc, Canada). Leak current was subtracted. Current densities were calculated by dividing the current to the membrane capacitance $(\mathrm{Cm})$. Steady-state activation and inactivation curves were fitted using a Boltzmann equation: $I / I_{\max }=A /\left\{1.0+\exp \left[\left(V_{1 / 2}-\mathrm{V}\right) / \mathrm{k}\right\}\right.$ with $\mathrm{k}>0$ for the activation curve and $\mathrm{k}<0$ for the inactivation curve.

Action potential clamp: In order to record specific currents during AP cycles, and especially during the depolarization phase, cells membrane potential was clamped according to voltageAP-like protocols. Representative APs acquired from spontaneously beating control hiPS-CMs 
CVR-2019-1019R2

with $\left(\mathrm{dV} / \mathrm{dt}_{\max }=100 \mathrm{~V} / \mathrm{s} ; A P \mathrm{AP}_{90}=280 \mathrm{~ms} ; \mathrm{RMP}=-83 \mathrm{mV}\right)$ or without $\left(\mathrm{dV} / \mathrm{dt}_{\max }=12 \mathrm{~V} / \mathrm{s}\right.$; $\mathrm{APD}_{90}=300 \mathrm{~ms} ; \mathrm{RMP}=-57 \mathrm{mV}$ ) in silico $\mathrm{I}_{\mathrm{K} 1}$ injection were selected. Activated sodium current during AP was measured by subtracting traces before and after adding $30 \mu \mathrm{M}$ tetrodotoxin TTX in $\mathrm{I}_{\mathrm{Na}}$-specific intracellular and extracellular (with $130 \mathrm{mM} \mathrm{NaCl}$ concentration) solutions (Supplemental Table 5). $\mathrm{I}_{\mathrm{Ca}, \mathrm{L}}$ was considered as the Nifedipine-sensitive $(4 \mu \mathrm{M})$ calcium current recorded using $\mathrm{I}_{\mathrm{Ca}, \mathrm{L}}$ solutions (Supplemental Table 5).

\subsection{Luciferase assay}

SCN5A BS2- (from -261 to +613 bp of the TSS) and BS2+ (from -261 to $+1072 \mathrm{bp}$ from TSS) Plasmids (150 ng), pGL2-Renilla (15 ng) with or without GATA4 expressing vector (150 ng) and with or without either of the wild-type or mutated forms of IRX5 expressing vectors (150 ng) were transfected into HEK293 cells using Lipofectamine 2000 (Thermo Fisher Scientific). DNA quantities were equalized in each condition using empty pcDNA3.1. Cells were harvested 48 hours later and luciferase activity was measured using Dual Luciferase reporter assay system (Promega).

\subsection{Microscale Thermophoresis (MST)}

MST was used to verify protein interaction with DNA according to Nanotemper instructions. Briefly, HEK293 cells transfected by IRX5-GFP expressing vector were used to produce fluorescently labeled IRX5 protein. Cell lysates were prepared using a buffer containing $20 \mathrm{mM}$ Tris $\mathrm{HCl}, 130 \mathrm{mM} \mathrm{NaCl}, 1 \% \mathrm{NP} 40$, and protease inhibitors cocktail. Titration series were performed to obtain varying concentrations of SCN5A plasmids. Measurements were accomplished in standard treated capillaries on Monolith NT.115 instrument using $80 \%$ of laser power.

\subsection{Statistical analysis}

Results are expressed as mean \pm SEM. Comparisons were made using Student $t$-test, or twoway ANOVA with Bonferroni post-hoc test for repeated measures. Values of $p<0.05$ were considered statistically significant. Statistical analyses were performed with GraphPad Prism software. 


\section{Results}

\subsection{IRX5 TF expression correlates with conduction genes expression in human cardiac} tissues

Transcriptomic analyses were performed to obtain a systemic view of IRX5-driven gene regulations and to direct further functional analyses. In order to identify evolutionary-conserved IRX5-coregulated genes in contractile tissues, expression profiles of cardiac genes including ion channels and TFs were compared between murine and human tissues. Overall, the global gene expression contrast profile between atrial and ventricular murine tissues were conserved in human samples (Figure 1A). The cluster of genes that are more expressed in ventricular tissues, included IRX5 and several genes involved in cardiac conduction, such as SCN5A, which encodes the main cardiac sodium channel $\mathrm{Na}_{\mathrm{v}} 1.5$ (Figure 1A). Then, the correlations between IRX5 gene expression level and those of sodium channels and connexins $(\mathrm{Cx})$, the two main families of genes implicated in cardiac conduction in humans, were investigated in the ventricles. Interestingly, SCN5A and GJA5, encoding one of the main cardiac Cx, Cx40, showed the strongest correlation coefficient with IRX5, respectively 0,62 and 0,60 (Figure 1B). In accordance with these results and confirming previous reports [22,31-34], both $\mathrm{Na}_{\mathrm{v}} 1.5$ and Cx40 shared a gradient of protein expression similar to that of IRX5 throughout the human ventricular wall with a higher level in subendocardium, which also includes Purkinje fibers, as compared to subepicardium (Figure 1C).

Taken together, these analyses shed light on the importance of studying the role of IRX5 in the regulation of cardiac ventricular genes, and more specifically in the regulation of players of cardiac electrical conduction in human ventricles. The analysis of the role of IRX5 in humans was then pursued using hiPSCs obtained from three non-diseased individuals (shown as averaged) as well as from two patients carrying different loss-of-function (LOF) mutations in IRX5 gene associated to a prolonged QRS interval in comparison with normal limits in children on the ECG [35], together with a right bundle branch block [6,36] (Figure S2A).

\subsection{IRX5-mutated hiPS-CMs derived from HMMS patients are a relevant model to study IRX5 role.}

Dermal fibroblasts of two Hamamy patients who are homozygous carriers of either the A150Por the N166K-IRX5 mutation [6] and of 3 intra- and extra-familial control subjects were reprogrammed into hiPSCs. Mutations were confirmed by sequencing in hiPSCs (Figure S2B). 
Genome integrity was validated using SNP analysis (data not shown). Expression of pluripotency markers were verified in hiPSCs (Figure S2C-E).

We then investigated whether all hiPSC lines differentiated in a comparable manner. Principal Component Analysis (PCA) of individual transcriptomic profiles as well as correlation analysis showed that samples mainly clustered according to their differentiation stage (Figure S3A and 3B). Furthermore, all control and IRX5-mutated hiPS-CMs presented a similar global change in gene expression compared to that of hiPSCs (Figure S3C). These data showed that all hiPSCs, irrespectively of their genetic background, differentiated similarly into cardiac cells. Immunostaining analysis showed that striated troponin I was present in CMs derived from each hiPSC line (Figure 2A) and a known marker for ventricular electrical activity, connexin 43, was present in all lines (Figure S4). Expression of specific markers for atrial and ventricular cells revealed the presence of both these cell types in the differentiated hiPSCs, but not their proportions (Figure S5). Action potential recordings further confirmed the presence of atriallike and ventricular-like cells, but also nodal-like cells, in proportions that were comparable in control and mutated hiPS-CMs, with the ventricular-like type forming the majority of hiPSCMs (Figure 2B). Altogether, these data confirmed that control and IRX5-mutated hiPSCs differentiated similarly into cardiomyocytes, and therefore that hiPS-CMs are a relevant model to investigate the role of IRX5 in ventricular electrical conduction.

Regarding the impact of IRX5 mutations on its own expression, transcriptional analysis and nuclear protein expression revelation showed comparable IRX5 expression levels in control and IRX5-mutated hiPS-CMs (Figure 2C-2D). Finally, immunostainings of hiPS-CMs constantly showed localization of IRX5 in CM nuclei (Figure 2A). These data showed that A150P and N166K mutations neither alter IRX5 expression nor its localization in hiPS-CMs.

\subsection{Key cardiac electrical conduction gene expression depends on IRX5}

Global transcriptomic analysis in hiPS-CMs, using 3'SRP, unveiled 745 genes differentially expressed between control and IRX5-mutated cells. These include several cardiac electrical conduction genes such as HEY2 and TBX5 transcription factors, that have been shown to present a gradient of expression within the ventricular wall opposite to the one of IRX5, suggesting that they may be negatively regulated by IRX5 (Figure 3A) [33,34,37]. Using highthroughput real-time RT-PCR (TLDA) we also analyzed a set of 96 genes, including mostly genes with low expression level that could not be properly detected using 3'SRP (Figure 3B). Overall, for the genes detected with both techniques, expression profiles were concordant (Figure S6). Biological pathway enrichment analysis revealed that differentially expressed 
genes were enriched in pathways involved in cardiac structure, in the regulation of cardiac conduction, and in muscle contraction, and more specifically in the cardiac conduction and phase 0 AP-depolarization functions, mainly linked to the activity of SCN5A and GJA5 (Figure 3C, Figure S3D). More precisely, analyses of IRX5-A150P and -N166K hiPS-CMs concordantly showed major mRNA and protein expression reductions of both SCN5A and GJA5 (Figure 4A-4B). Also, confocal microscopy further confirmed that $\mathrm{Na}_{\mathrm{v}} 1.5$ and $\mathrm{Cx} 40$ expression was decreased in troponin T positive IRX5-A150P and -N166K mutated hiPS-CMs (Figure $4 C)$.

Taken together, hiPS-CMs carrying IRX5 LOF mutations, exhibited altered expression of key genes involved in cardiac electrical conduction, suggesting a role for IRX5 in the direct transcriptional control of these genes.

\subsection{AP depolarization and INa density are modulated by IRX5}

Given the delayed ventricular conduction phenotype observed in HMMS, a slower AP depolarization in patient-derived hiPS-CMs was expected. However, the maximal depolarization velocity $\left(\mathrm{dV} / \mathrm{dt}_{\max }\right)$ of ventricular APs, was not statistically reduced in IRX5mutated hiPS-CMs (Figure 5A). We hypothesized that hiPS-CMs being immature and lacking $\mathrm{I}_{\mathrm{K} 1}$, cellular resting membrane potentials (RMPs) of hiPS-CMs were too depolarized (around $60 \mathrm{mV}$, as shown in Figure 5B), and may not be suitable for proper activation of depolarizing currents. To overcome this issue, an in-silico $\mathrm{I}_{\mathrm{K} 1}$ injection was performed. It brought ventricular RMPs to about $-80 \mathrm{mV}$ (Figure $5 \mathrm{~B}$ ) and induced (i) an increase in $\mathrm{dV} / \mathrm{dt}_{\max }$ back to physiological values in control hiPS-CMs and (ii) a significant reduction in $\mathrm{dV} / \mathrm{dt}_{\max }$ in $I R X 5$-mutated hiPSCMs (Figure 5C). The contribution of $\mathrm{I}_{\mathrm{Na}}$ and $\mathrm{I}_{\mathrm{Ca}, \mathrm{L}}$ to AP depolarization as a function of $\mathrm{I}_{\mathrm{K} 1}$ injection was then investigated. They were measured when ventricular-like AP voltages, recorded with or without $\mathrm{I}_{\mathrm{K} 1}$ injection, were applied to control hiPS-CMs. Without $\mathrm{I}_{\mathrm{K} 1}$ injection, $\mathrm{I}_{\mathrm{Ca}, \mathrm{L}}$ contribution to the depolarization phase was greater than that of $\mathrm{I}_{\mathrm{Na}}$, while with $\mathrm{I}_{\mathrm{K} 1}$ injection, $\mathrm{I}_{\mathrm{Na}}$ became the main contributor (Figure 5D). This suggests that the $\mathrm{dV} / \mathrm{dt}_{\max }$ reduction observed in IRX5-mutated hiPS-CMs under $\mathrm{I}_{\mathrm{K} 1}$ injection was due to a functional reduction of $\mathrm{I}_{\mathrm{Na}}$, but not of $\mathrm{I}_{\mathrm{Ca}, \mathrm{L}}$. Confirming this hypothesis, $\mathrm{I}_{\mathrm{Na}}$ was reduced by half in IRX5-mutated hiPSCMs (Figure 5E and Figure S7A) without any change in the activation and inactivation curves as well as in the recovery from inactivation kinetics (Figure S7B-S7C and Supplemental Table 6). In contrast to $\mathrm{I}_{\mathrm{Na}}$ reduction, no modification in $\mathrm{I}_{\mathrm{Ca}, \mathrm{L}}$ density was observed (Figure $5 \mathrm{~F}$ ). Together with the SCN5A expression alteration, these data suggest that a slower ventricular AP depolarization due to $\mathrm{I}_{\mathrm{Na}}$ reduction may participate to the prolonged QRS observed in HMMS. 


\subsection{IRX5 interacts with $S C N 5 A$ and $G J A 5$ promoters}

Considering the altered transcription of SCN5A and GJA5 induced by IRX5 LOF, we explored whether IRX5 regulates directly their promoters. An in-silico analysis showed that SCN5A promoter region includes three potential TF-binding sites (BS) for IRX5 (Figure 6A). In accordance with previous studies on mice [8], human GJA5 promoter region was free from any conserved IRX BS (Figure 6B). Immunoprecipitation of IRX5-associated chromatin showed an enrichment of SCN5A-BS2 in control hiPS-CMs, revealing an interaction with IRX5, but not in IRX5-mutated hiPS-CMs (Figure 6A). On the other hand, despite the absence of in-silico identification of conserved IRX-BS on GJA5 promoter, an interaction between IRX5 and GJA5 core promoter was found in control hiPS-CMs, that was again absent in IRX5-mutated hiPSCMs (Figure 6B). These data strongly suggest that IRX5 interacts with SCN5A and GJA5 promoters to regulate their expression in hiPS-CMs.

To further investigate the direct interaction between SCN5A promoter and IRX5, their binding affinity was evaluated. Two different DNA constructs containing SCN5A promoter were used: BS2+ plasmid, containing IRX5 BS2 and BS2- plasmid, lacking IRX5 BS2. Interestingly, IRX5 protein did bind to BS2+ plasmid but not to BS2- plasmid, confirming that IRX5 protein binds to $S C N 5 A$ promoter when $\mathrm{BS} 2$ is present (Figure 6C).

Finally, the functional consequences of IRX5 binding on SCN5A promoter were further evaluated using luciferase assay with the BS2+ plasmid construct. Unexpectedly, neither IRX5 nor its mutated forms activated the luciferase reporter gene (Figure 6D), indicating that another TF may be required to allow IRX5 to regulate SCN5A expression. This prompted us to investigate the role of potential critical partners for IRX5, already known to be important for regulation of cardiac development and electrical function, such as GATA4. GATA4, a cardiogenic TF, has indeed been previously shown to regulate SCN5A expression [38] and an interaction between Irx 5 and another member of the Gata family of TFs, Gata3, has been unveiled during craniofacial development [6].

\subsection{IRX5 and GATA4 cooperatively regulate $S C N 5 A$ expression in human cardiomyocytes}

Comparably in human cardiac ventricular samples and control hiPS-CMs, among GATA family members, GATA4 was the most strongly expressed (Figure 7A). In control hiPS-CMs, GATA4 co-immunoprecipitated with IRX5 and this interaction was not altered in IRX5-mutated hiPSCMs (Figure 7B). As $S C N 5 A$ promoter contains two sites for GATA4 binding ( $B S a$ and $B S b$ ) [38], ChIP experiments using IRX5 antibody showed that IRX5 interacted with GATA4 BSb region in control and IRX5-mutated hiPS-CMs (Figure 7C). Binding affinity analysis further 
CVR-2019-1019R2

validated the direct interaction between $S C N 5 A$ promoter and the heterodimer IRX5-GATA4, as a binding was observed when both IRX5 and GATA4 proteins were mixed with BS2plasmid, in opposition to when IRX5 alone was mixed with BS2- plasmid (Figure S8). Therefore, IRX5 not only binds directly to $B S 2$ on $S C N 5 A$ promoter but also binds the $B S b$ site together with GATA4. Finally, to further dissect the role of IRX5 and GATA4 on SCN5A transcription activation, luciferase assays were performed with plasmids containing either $B S b$ only (BS2- plasmid) or BSb and BS2 (BS2+ plasmid). Co-transfection of GATA4 expressing vector with either plasmid triggered a similar increase in luciferase activity, confirming that GATA4 activated $S C N 5 A$ promoter through a direct interaction with $B S b$ (Figure 7D). Interestingly, when IRX5 was added to these combinations, it potentiated by 1.6 times the effect of GATA4 on BS2- plasmid, and by 3.9 times the effect of GATA4 on BS2+ plasmid (Figure 7D). This further demonstrated that the direct binding of IRX5 to $B S 2$ is important for proper activation of SCN5A expression. Conversely, no potentiation of GATA4 activation of SCN5A promoter was observed when A150P- or N166K-mutated IRX5 were added to the various combinations (Figure 7D). Interestingly, in contrast to IRX5 and SCN5A, which shared similarly-graded expression patterns, GATA4 was homogeneously expressed both in atria and ventricles, and throughout the ventricular wall (Figure S9A-D). This suggests that GATA4 triggers basal expression of SCN5A throughout cardiac tissues, while IRX5 is responsible for the establishment of its expression gradient. 


\section{Discussion}

This study demonstrates that IRX5 TF is instrumental for proper control of electrical activity in human cardiomyocytes. hiPS-CMs generated from patients with rare mutations in IRX5 recapitulated their clinical features of ventricular depolarization delay, through an alteration in the regulation of major sodium channel and connexin-encoding gene expression.

\subsection{HiPSCs as a model to study TFs}

It is commonly acknowledged that stem cell-derived cardiomyocytes fail to fully recapitulate adult CM features [39]. Accordingly, expression of both Connexin 40 and Connexin 43 was observed in the hiPS-CMs. While the adult ventricular myocardium is known to express connexin 43 but nearly no connexin 40, known to be specifically expressed in adult Purkinje fibers, prenatal ventricular myocardium expresses connexin 43 and connexin 40 in an overlapping pattern [40]. Thus, the fetal-like phenotype of ventricular hiPS-CMs may explain why they express not only connexin 43 but also connexin 40. Nevertheless, hiPS-CMs have been used successfully so far in more than 35 studies of cardiac arrhythmic diseases and channelopathies [39]. Recently, 2 studies showed the role of TFs in cellular dysfunction associated to cardiac morphogenetic and electrical defects using hiPS-CMs [41,42]. The present work additionally enforces the use of hiPSCs as a relevant model for studying the role of TF in the regulation of cardiac electrical conduction. Indeed, with in-silico $\mathrm{I}_{\mathrm{K} 1}$ injection, we revealed cellular phenotypic traits that are consistent with the patient's clinical phenotype, e.g. QRS complex prolongation observed on the patient's ECG.

\subsection{Interspecies regulatory pathway differences}

Electrophysiological properties across species are known to be different [43], suggesting that the roles of cardiac TFs can differ from one species to another. Here, in agreement with this postulate, comparably to what was previously demonstrated for Irx3 and its regulation of fast conduction in the murine heart [8], an induction of GJA5 expression by IRX5 has been found in human iPS-derived cardiomyocytes. However, Irx $5 \mathrm{KO}$ mice did not exhibit conduction delay and murine Irx5 was not shown to regulate the expression of $C x$ [28].

Moreover, the patients, unlike Irx5KO mice, do not display ventricular repolarization abnormalities, but a conduction defect. Indeed, the deletion of Irx5 in mice leads to the abolishment of the $\mathrm{T}$ wave on the ECG due to the loss of the transmural gradient of expression of $K c n d 2$, at the root of one major player of ventricular repolarization in mice, $\mathrm{I}_{\mathrm{to}}$, but not in human heart, where $K C N D 3$ constitute the predominant alpha-subunit generating $\mathrm{I}_{\text {to }}$ [22]. 
Another argument in favor of interspecies differences in gene regulation by IRX TFs is that, due to its transmural gradient of expression, Irx 5 establishes gradients of expression for its target genes. That is how, in mice, Kcnd2 ventricular gradient is known to be established. In human, it is unlikely that IRX5 regulates KCND3 expression, as, in opposition to IRX5, its expression is uniform across the ventricular wall [7,22].

Along with this rationale, in this study, using patient-derived cardiomyocytes, a role for IRX5 in the regulation of the expression of the major actors of conduction of the electrical influx, sodium channel subunit and connexin, was elucidated. These data illustrate interspecies differences in the mechanism of action of Iroquois TFs, demonstrating the importance of using appropriate models to study human diseases.

\subsection{Complex regulatory pathway underlies electrical conduction}

Conduction of electrical influx throughout the ventricles is mediated not only by connexins but also by inward currents responsible for the depolarization phase of APs. Here, among these inward currents ( $\mathrm{I}_{\mathrm{Na}}$ and $\left.\mathrm{I}_{\mathrm{Ca}, \mathrm{L}}\right), \mathrm{I}_{\mathrm{Na}}$ reduction has been identified as the trigger of the impaired AP upstroke velocity in mutated hiPS-CMs. Concordantly, SCN5A mRNA expression level is significantly reduced by 2.8 and 4.6 folds, in A150P and N166K hiPS-CMs as compared to control cells, respectively. At the protein level and as discussed above, Nav1.5 protein expression level is significantly reduced by 3 and 3.3 folds, in A150P and N166K hiPS-CMs as compared to control cells, respectively. And finally, at the functional level, $\mathrm{I}_{\mathrm{Na}}$ current density is significantly reduced by 2 and 2.7 folds, in A150P and N166K hiPS-CMs as compared to control cells, respectively. In agreement with a direct transcriptional regulation, IRX5 binds to and activates SCN5A proximal promoter in control hiPS-CMs whereas mutations in IRX5 prevent this interaction. Surprisingly, at the functional level, luciferase assays showed that IRX5 alone was not able to activate $S C N 5 A$, suggesting that regulation of $S C N 5 A$ is due to a combinatorial effect of several factors. In accordance, IRX5 and GATA4 have been found to interact with each other allowing IRX5 to bind to a previously described GATA4 BS on SCN5A promoter and to enhance GATA4 effect on SCN5A activation. Interestingly, while IRX5 and SCN5A display a comparable gradient of expression through the ventricular wall, as well as between atria and ventricles, GATA4 has a more uniform pattern of expression. We thus hypothesized that GATA4 and IRX5 could act cooperatively where GATA4 may be important for basal expression of SCN5A in human cardiomyocytes while IRX5 creates its gradients of expression in the heart. Genetic expression and/or function abnormalities of SCN5A together with conduction defects have been previously linked to other rare arrhythmic diseases, such as 
CVR-2019-1019R2

Brugada syndrome $[44,45]$. Thus, the current study elaborating the role of IRX5 in the control of ventricular conduction through the regulation of SCN5A presents a framework for future studies on its potential implication in other complex diseases such as Brugada syndrome.

\subsection{Study limitations}

Arrhythmic diseases often present with a wide spectrum of phenotypes, even among patients belonging to the same family. The individual genetic background is thought to play a major role in this heterogeneity. In the context of hiPSC-based disease modeling, the use of isogenic control, where the genetic variant has been corrected in the patient iPS cell line, is increasingly employed. The present study aimed at dissecting IRX5 regulatory mechanisms of human cardiac electrical function by modeling HMMS. Therefore, we chose to perform a comparative analysis between control and two hiPSC lines obtained from two HMMS patients belonging to different families and harboring different LOF mutations in IRX5. For all studied parameters, similar results have been obtained for both types of mutated hiPS-CMs as compared to control cells, strongly supporting a specific role for IRX5 in the pathological phenotype and thereby minimizing the relevance of using isogenic controls.

We suggested the presence of $\mathrm{Cx} 40$ and Nav1.5 protein gradients through human adult ventricular wall (Figure 1C), although the presence of Purkinje fibers in the endocardial samples likely participate to the expression differences. Indeed, higher levels of protein and or current have been observed in Purkinje fibers as compared to endocardial myocytes, in the adult heart $[46,47]$.

\section{Conclusion}

In conclusion, the present data suggest that functional IRX5 is essential for regulation of sodium channel- and connexin-gene expression, ensuring proper conduction of the electrical influx between cardiomyocytes. Furthermore, a role for this transcription factor in the orchestration of the gene expression program governing ventricular electrical depolarization in human was uncovered, bringing to light a new potential option for therapeutic intervention. 


\section{Acknowledgments:}

The authors would like to thank the Genomics and Bioinformatics Core Facility (GenoBiRD, Biogenouest), the Cytometry facility (CytoCell), the iPS core facility, and the Cellular and Tissular Imaging Core Facility (MicroPICell) of Nantes University, for their technical support. The authors also would like to thank Dan Roden for the gift of SCN5A plasmids, and Sophie Demolombe for helping with mouse studies.

\section{Data availability:}

The authors declare that all data supporting the findings of this study are available within the article and its supplementary information files or from the corresponding author upon reasonable request.

All read sequence data and sample annotations generated for this paper are available at European Nucleotide Archive (ENA) with accession number PRJEB39654.

\section{Sources of Funding:}

This work was funded by grants from The National Research Agency [HEART iPS ANR-15CE14-0019-01], and La Fédération Française de Cardiologie. Nathalie Gaborit was laureate of fellowships from Fondation Lefoulon-Delalande and International Incoming Fellowship FP7-PEOPLE-2012-IIF [PIIF-GA-2012-331436]. Zeina R. Al Sayed is supported by Eiffel scholarship program of Excellence (Campus France), by Doctoral School of Science and Technology-Lebanese University and The Fondation Genavie.

Conflict of interest: None declared.

\section{Authors contributions:}

Zeina R. Al-Sayed contributed to the acquisition, interpretation of data, and writing of the report; Robin Canac contributed to data acquisition; Bastien Cimarosti contributed to data acquisition; Carine Bonnard contributed to clinical data acquisition; Jean-Baptiste Gourraud contributed to clinical data analysis; Hanan Hamamy contributed to clinical data acquisition; Hulya Kayserili contributed to clinical data acquisition; Aurore Girardeau contributed to data acquisition; Mariam Jouni contributed to data acquisition; Nicolas Jacob contributed to data acquisition; Anne Gaignerie contributed to data acquisition; Caroline Chariau contributed to data acquisition; Laurent David contributed to data acquisition; Virginie Forest contributed to data acquisition; Céline Marionneau contributed to data acquisition; Flavien Charpentier contributed to writing of the report; Gildas Loussouarn contributed to data analysis, and writing 
CVR-2019-1019R2

of the report; Guillaume Lamirault contributed to data analysis, and writing of the report; Bruno Reversade contributed to clinical data acquisition; Kazem Zibara contributed to the writing of the report; Patricia Lemarchand contributed to the study design, interpretation of the data, and writing of the report; Nathalie Gaborit contributed to the study design, interpretation of the data, and writing of the report.

All authors discussed the results and contributed and approved the final manuscript. 


\section{References}

1. Pazoki R, Wilde AAM, Bezzina CR. Genetic Basis of Ventricular Arrhythmias. Curr Cardiovasc Risk Rep. 2010;4:454- 60.

2. Gourraud J-B, Barc J, Thollet A, Le Scouarnec S, Le Marec H, Schott J-J, Redon R, Probst V. The Brugada Syndrome: A Rare Arrhythmia Disorder with Complex Inheritance. Front Cardiovasc Med. 2016;3:9.

3. Eif VWW, Devalla HD, Boink GJJ, Christoffels VM. Transcriptional regulation of the cardiac conduction system. Nat Rev Cardiol. 2018;15;617-630.

4. $\mathrm{Hu} \mathrm{W}$, Xin Y, Zhang L, Hu J, Sun Y, Zhao Y. Iroquois Homeodomain transcription factors in ventricular conduction system and arrhythmia. Int J Med Sci. 2018;15:808-15.

5. Hamamy HA, Teebi AS, Oudjhane K, Shegem N, Ajlouni K. Severe hypertelorism, midface prominence, prominent/simple ears, severe myopia, borderline intelligence, and bone fragility in two brothers: New syndrome? Am J Med Genet A. 2007;143A:229-34.

6. Bonnard C, Strobl AC, Shboul M, Lee H, Merriman B, Nelson SF, Ababneh OH, Uz E, Güran T, Kayserili H, Hamamy H, Reversade B. Mutations in IRX5 impair craniofacial development and germ cell migration via SDF1. Nat Genet. 2012;44:709-13.

7. Costantini DL, Arruda EP, Agarwal P, Kim K-H, Zhu Y, Zhu W, Lebel M, Cheng CW, Park CY, Pierce SA, Guerchicoff A, Pollevick GD, Chan TY, Kabir MG, Cheng SH, Husain M, Antzelevitch C, Srivastava D, Gross GJ, Hui C, Backx PH, Bruneau BG. The Homeodomain Transcription Factor Irx5 Establishes the Mouse Cardiac Ventricular Repolarization Gradient. Cell. 2005;123:347-58.

8. Zhang S-S, Kim K-H, Rosen A, Smyth JW, Sakuma R, Delgado-Olguín P, Davis M, Chi NC, Puviindran V, Gaborit N, Sukonnik T, Wylie JN, Brand-Arzamendi K, Farman GP, Kim J, Rose RA, Marsden PA, Zhu Y, Zhou Y-Q, Miquerol L, Henkelman RM, Stainier DYR, Shaw RM, Hui C, Bruneau BG, Backx PH. Iroquois homeobox gene 3 establishes fast conduction in the cardiac His-Purkinje network. Proc Natl Acad Sci. 2011;108:13576-81.

9. Kim K-H, Rosen A, Hussein SMI, Puviindran V, Korogyi AS, Chiarello C, Nagy A, Hui $\mathrm{C}$, Backx PH. Irx3 is required for postnatal maturation of the mouse ventricular conduction system. Sci Rep. 2016;6:19197.

10. Marionneau C, Couette B, Liu J, Li H, Mangoni ME, Nargeot J, Lei M, Escande D, Demolombe S. Specific pattern of ionic channel gene expression associated with pacemaker activity in the mouse heart. J Physiol. 2005;562:223-34.

11. Jouni M, Si-Tayeb K, Es-Salah-Lamoureux Z, Latypova X, Champon B, Caillaud A, Rungoat A, Charpentier F, Loussouarn G, Baró I, Zibara K, Lemarchand P, Gaborit N. Toward Personalized Medicine: Using Cardiomyocytes Differentiated From UrineDerived Pluripotent Stem Cells to Recapitulate Electrophysiological Characteristics of Type 2 Long QT Syndrome. J Am Heart Assoc. 2015;4:e002159.

12. Es-Salah-Lamoureux Z, Jouni M, Malak OA, Belbachir N, Al Sayed ZR, Gandon-Renard M, Lamirault G, Gauthier C, Baró I, Charpentier F, Zibara K, Lemarchand P, Beaumelle 
B, Gaborit N, Loussouarn G. HIV-Tat induces a decrease in $\mathrm{IKr}$ and IKs via reduction in phosphatidylinositol-(4,5)-bisphosphate availability. J Mol Cell Cardiol. 2016;99:1-13.

13. Si-Tayeb K, Noto FK, Nagaoka M, Li J, Battle MA, Duris C, North PE, Dalton S, Duncan SA. Highly efficient generation of human hepatocyte-like cells from induced pluripotent stem cells. Hepatol Baltim Md. 2010;51:297- 305.

14. Wang W-X, Danaher RJ, Miller CS, Berger JR, Nubia VG, Wilfred BS, Neltner JH, Norris CM, Nelson PT. Expression of miR-15/107 family microRNAs in human tissues and cultured rat brain cells. Genomics Proteomics Bioinformatics. 2014;12:19- 30.

15. Mestdagh P, Van Vlierberghe P, De Weer A, Muth D, Westermann F, Speleman F, Vandesompele J. A novel and universal method for microRNA RT-qPCR data normalization. Genome Biol. 2009;10:R64.

16. Bockmeyer CL, Säuberlich K, Wittig J, Eßer M, Roeder SS, Vester U, Hoyer PF, Agustian PA, Zeuschner P, Amann K, Daniel C, Becker JU. Comparison of different normalization strategies for the analysis of glomerular microRNAs in IgA nephropathy. Sci Rep. 2016;6:31992.

17. Kilens S, Meistermann D, Moreno D, Chariau C, Gaignerie A, Reignier A, Lelièvre Y, Casanova M, Vallot C, Nedellec S, Flippe L, Firmin J, Song J, Charpentier E, Lammers J, Donnart A, Marec N, Deb W, Bihouée A, Caignec CL, Pecqueur C, Redon R, Barrière P, Bourdon J, Pasque V, Soumillon M, Mikkelsen TS, Rougeulle C, Fréour T, David L. Parallel derivation of isogenic human primed and naive induced pluripotent stem cells. Nat Commun. 2018;9:360.

18. Croft D, Mundo AF, Haw R, Milacic M, Weiser J, Wu G, Caudy M, Garapati P, Gillespie M, Kamdar MR, Jassal B, Jupe S, Matthews L, May B, Palatnik S, Rothfels K, Shamovsky V, Song H, Williams M, Birney E, Hermjakob H, Stein L, D’Eustachio P. The Reactome pathway knowledgebase. Nucleic Acids Res. 2014;42:D472- 7.

19. Fabregat A, Korninger F, Viteri G, Sidiropoulos K, Marin-Garcia P, Ping P, Wu G, Stein L, D'Eustachio P, Hermjakob H. Reactome graph database: Efficient access to complex pathway data. PLOS Comput Biol. 2018;14:e1005968.

20. Medina PP, Nolde M, Slack FJ. OncomiR addiction in an in vivo model of microRNA21-induced pre-B-cell lymphoma. Nature. 2010;467:86-90.

21. Sartor MA, Leikauf GD, Medvedovic M. LRpath: a logistic regression approach for identifying enriched biological groups in gene expression data. Bioinforma Oxf Engl. 2009;25:211-7.

22. Gaborit N, Varro A, Le Bouter S, Szuts V, Escande D, Nattel S, Demolombe S. Genderrelated differences in ion-channel and transporter subunit expression in non-diseased human hearts. J Mol Cell Cardiol. 2010;49:639-46.

23. Bilioni A, Craig G, Hill C, McNeill H. Iroquois transcription factors recognize a unique motif to mediate transcriptional repression in vivo. Proc Natl Acad Sci U S A.

2005;102:14671-6. 
24. Berger MF, Badis G, Gehrke AR, Talukder S, Philippakis AA, Peña-Castillo L, Alleyne TM, Mnaimneh S, Botvinnik OB, Chan ET, Khalid F, Zhang W, Newburger D, Jaeger SA, Morris QD, Bulyk ML, Hughes TR. Variation in Homeodomain DNA Binding Revealed by High-Resolution Analysis of Sequence Preferences. Cell. 2008;133:126676.

25. Noyes MB, Christensen RG, Wakabayashi A, Stormo GD, Brodsky MH, Wolfe SA. Analysis of Homeodomain Specificities Allows the Family-wide Prediction of Preferred Recognition Sites. Cell. 2008;133:1277-89.

26. Peters T, Dildrop R, Ausmeier K, Rüther U. Organization of mouse Iroquois homeobox genes in two clusters suggests a conserved regulation and function in vertebrate development. Genome Res. 2000;10:1453- 62.

27. Houweling AC, Dildrop R, Peters T, Mummenhoff J, Moorman AF, Rüther U, Christoffels VM. Gene and cluster-specific expression of the Iroquois family members during mouse development. Mech Dev. 2001;107:169- 74.

28. Gaborit N, Sakuma R, Wylie JN, Kim K-H, Zhang S-S, Hui C-C, Bruneau BG. Cooperative and antagonistic roles for Irx 3 and Irx 5 in cardiac morphogenesis and postnatal physiology. Dev Camb Engl. 2012;139:4007- 19.

29. Putten VERM, Mengarelli I, Guan K, Zegers JG, Ginneken VGAC, Verkerk AO, Wilders R. Ion channelopathies in human induced pluripotent stem cell derived cardiomyocytes: a dynamic clamp study with virtual IK1. Front Physiol. 2015;6:7.

30. Bett GC, Kaplan AD, Lis A, Cimato TR, Tzanakakis ES, Zhou Q, Morales MJ, Rasmusson RL. Electronic « expression » of the inward rectifier in cardiocytes derived from human-induced pluripotent stem cells. Heart Rhythm. 2013;10:1903-10.

31. Gaborit N, Le Bouter S, Szuts V, Varro A, Escande D, Nattel S, Demolombe S. Regional and tissue specific transcript signatures of ion channel genes in the nondiseased human heart. J Physiol. 2007;582:675-93.

32. Remme CA, Verkerk AO, Hoogaars WMH, Aanhaanen WTJ, Scicluna BP, Annink C, van den Hoff MJB, Wilde AAM, Veen TAB, Veldkamp MW, Bakker JMT, Christoffels VM, Bezzina CR. The cardiac sodium channel displays differential distribution in the conduction system and transmural heterogeneity in the murine ventricular myocardium. Basic Res Cardiol. 2009;104:511- 22.

33. Veerman CC, Podliesna S, Tadros R, Lodder EM, Mengarelli I, Jonge B de, Beekman L, Barc J, Wilders R, Wilde AAM, Boukens BJ, Coronel R, Verkerk AO, Remme CA, Bezzina CR. The Brugada Syndrome Susceptibility Gene HEY2 Modulates Cardiac Transmural Ion Channel Patterning and Electrical HeterogeneityNovelty and Significance. Circ Res. 2017;121:537- 48.

34. Rosati B, Grau F, Mckinnon D. Regional variation in mRNA transcript abundance within the ventricular wall. J Mol Cell Cardiol. 2006;40:295-302.

35. Rijnbeek PR, Witsenburg M, Schrama E, Hess J, Kors JA. New normal limits for the paediatric electrocardiogram. Eur Heart J. 2001;22:702- 11. 
36. Surawicz B, Childers R, Deal BJ, Gettes LS, Bailey JJ, Gorgels A, Hancock EW, Josephson M, Kligfield P, Kors JA, Macfarlane P, Mason JW, Mirvis DM, Okin P, Pahlm O, Rautaharju PM, van Herpen G, Wagner GS, Wellens H, American Heart Association Electrocardiography and Arrhythmias Committee, Council on Clinical Cardiology, American College of Cardiology Foundation, Heart Rhythm Society. AHA/ACCF/HRS recommendations for the standardization and interpretation of the electrocardiogram: part III: intraventricular conduction disturbances: a scientific statement from the American Heart Association Electrocardiography and Arrhythmias Committee, Council on Clinical Cardiology; the American College of Cardiology Foundation; and the Heart Rhythm Society. Endorsed by the International Society for Computerized Electrocardiology. J Am Coll Cardiol. 2009;53:976- 81.

37. Hatcher CJ, Goldstein MM, Mah CS, Delia CS, Basson CT. Identification and localization of TBX5 transcription factor during human cardiac morphogenesis. Dev Dyn. 2000;219:90-5.

38. Tarradas A, Pinsach-Abuin M, Mackintosh C, Llorà-Batlle O, Pérez-Serra A, Batlle M, Pérez-Villa F, Zimmer T, Garcia-Bassets I, Brugada R, Beltran-Alvarez P, Pagans S. Transcriptional regulation of the sodium channel gene (SCN5A) by GATA4 in human heart. J Mol Cell Cardiol. 2017;102:74-82.

39. Giacomelli E, Mummery CL, Bellin M. Human heart disease: lessons from human pluripotent stem cell-derived cardiomyocytes. Cell Mol Life Sci CMLS. 2017;74:371139.

40. Kempen MJ, Vermeulen JL, Moorman AF, Gros D, Paul DL, Lamers WH. Developmental changes of connexin40 and connexin43 mRNA distribution patterns in the rat heart. Cardiovasc Res. 1996;32:886-900.

41. Ang Y-S, Rivas RN, Ribeiro AJS, Srivas R, Rivera J, Stone NR, Pratt K, Mohamed TMA, Fu J-D, Spencer CI, Tippens ND, Li M, Narasimha A, Radzinsky E, Moon-Grady AJ, Yu H, Pruitt BL, Snyder MP, Srivastava D. Disease Model of GATA4 Mutation Reveals Transcription Factor Cooperativity in Human Cardiogenesis. Cell. Cell. 2016;167:1734-1749.e22.

42. Caballero R, Utrilla RG, Amorós I, Matamoros M, Pérez-Hernández M, Tinaquero D, Alfayate S, Nieto-Marín P, Guerrero-Serna G, Liu Q-H, Ramos-Mondragón R, PonceBalbuena D, Herron T, Campbell KF, Filgueiras-Rama D, Peinado R, López-Sendón JL, Jalife J, Delpón E, Tamargo J. Tbx20 controls the expression of the KCNH2 gene and of hERG channels. Proc Natl Acad Sci. 2017;114:E416-25.

43. Muszkiewicz A, Britton OJ, Gemmell P, Passini E, Sánchez C, Zhou X, Carusi A, Quinn TA, Burrage K, Bueno-Orovio A, Rodriguez B. Variability in cardiac electrophysiology: Using experimentally-calibrated populations of models to move beyond the single virtual physiological human paradigm. Prog Biophys Mol Biol. 2016;120:115- 27.

44. Gaborit N, Wichter T, Varro A, Szuts V, Lamirault G, Eckardt L, Paul M, Breithardt G, Schulze-Bahr E, Escande D, Nattel S, Demolombe S. Transcriptional profiling of ion channel genes in Brugada syndrome and other right ventricular arrhythmogenic diseases. Eur Heart J. 2009;30:487-96. 
45. Juang J-MJ, Tsai C-T, Lin L-Y, Liu Y-B, Yu C-C, Hwang J-J, Chen J-J, Chiu F-C, Chen W-J, Tseng C-D, Chiang F-T, Yeh H-M, Sherri Yeh S-F, Lai L-P, Lin J-L. Unique clinical characteristics and SCN5A mutations in patients with Brugada syndrome in Taiwan. J Formos Med Assoc. 2015;114:620- 6.

46. Lin X, Liu N, Lu J, Zhang J, Anumonwo JMB, Isom LL, Fishman GI, Delmar M. Subcellular heterogeneity of sodium current properties in adult cardiac ventricular myocytes. Heart Rhythm. 2011;8:1923-30.

47. Gros D, Jarry-Guichard T, Ten Velde I, de Maziere A, van Kempen MJ, Davoust J, Briand JP, Moorman AF, Jongsma HJ. Restricted distribution of connexin40, a gap junctional protein, in mammalian heart. Circ Res. 1994;74:839- 51. 


\section{Figure legends:}

\section{Figure 1: IRX5 TF and conduction genes expression in human cardiac tissues.}

A. Heatmap displaying expression level of 212 cardiac genes (ion channels and TFs) in murine atrial and ventricular tissues measured by TLDA $(-\Delta \mathrm{Ct})$, and in human atrial and left ventricular samples (GTEx). Murine genes were clustered using hierarchical ascending method with an uncentered correlation metric and average linkage. Heatmap of the same genes was obtained in human tissues based on the murine cluster, in a supervised hierarchical manner. Yellow and blue indicate high and low expression levels respectively. Representative genes of the ventricular-specific gene cluster are listed in the yellow box.

B. Comparative analysis of the expression pattern of genes encoding sodium channels and gap junction proteins in human left ventricular tissues, to the IRX5 gene expression pattern (GTEx). Samples were ordered according to their IRX5 expression levels (white/purple gradient from the lowest to the highest). Keeping the same sample organization, a white/purple color gradient was then similarly applied to selected genes involved in ventricular conduction of electrical influx (the median GTEx expression level in left ventricular samples is indicated on the left for each gene). Pearson correlation values between each sodium channel or gap junction gene and IRX5 expression profiles are shown using white/pink color gradients.

C. Representative immunoblots of IRX5, $\mathrm{Na}_{\mathrm{v}} 1.5$ and $\mathrm{Cx} 40$ levels in human protein lysates of ventricular subendocardial (Endo) and subepicardial (Epi) samples obtained from three human left (LV) and right ventricles (RV). Corresponding averaged IRX5, $\mathrm{Na}_{\mathrm{v}} 1.5$ and $\mathrm{CX} 40$ protein expression levels obtained from tissue samples of three individuals, technically replicated one to three times and normalized to Stain free.

\section{Figure 2: Characterization of IRX5-mutated hiPS-cardiomyocytes}

A. Illustrative immunostainings of IRX5 (red) and Troponin I (green) in hiPS-CMs, merged with a nuclear staining using DAPI (blue). To confirm nuclear localization of IRX5, XZ orthogonal planes are illustrated next to each picture.

B. Representative traces and distribution (as percentage) of nodal-like, atrial-like and ventricular-like cells, based on the analysis of AP parameters in spontaneously beating hiPSCMs (Ctrl: n=40; A150: n=78; N166K: n=80).

C. IRX5 mRNA expression level in control and mutated hiPS-CMs at day 28 of cardiac differentiation using TaqMan ${ }^{\circledR}$ technique (Ctrl: $n=22 ;$ A150P: $\left.n=8 ; N 166 K: n=14\right)$. 
D. Nuclear expression level of IRX5 protein in control and mutated hiPS-CMs, normalized to Stain free. Representative immunoblot showing IRX5 expression in the nuclear protein fraction (Ctrl: $n=11 ;$ A150P: $n=10 ; N 166 K: n=11)$.

\section{Figure 3: Transcriptomic aberrations in IRX5-mutated cardiomyocytes.}

A. Heatmap showing hierarchical clustering of expression profiles of the 745 differentially expressed genes obtained by 3'SRP in control ( $\mathrm{Ctrl}, \mathrm{n}=13)$ and IRX5-mutated $(\mathrm{n}=8)$ hiPSCMs at day 28 of differentiation. $41 \%$ and $59 \%$ genes were upregulated and downregulated in IRX5-mutated hiPS-CMs, respectively. Yellow and blue represent high and low expression levels respectively. Relevant genes implicated in the function or regulation of cardiac electrical conduction are highlighted on the right.

B. Histograms showing expression levels of differentially expressed genes in IRX5-mutated hiPS-CMs ( $\mathrm{n}=9)$ identified using TLDA, as compared to control hiPS-CMs $(\mathrm{n}=12) . *$ and $* *: \mathrm{p}<0.05$ and $\mathrm{p}<0.01 v s$. control, respectively $(t$ test $)$.

C. Top panel: Functional annotation of differentially expressed genes at day 28 of differentiation, obtained by 3'SRP and TaqMan. Histograms showing over-represented Reactome pathways. Only pathways with Enrichment Score $>2$ and $\mathrm{p}<0.05$ are shown. Bottom panel: Detailed muscle contraction pathway is represented.

Figure 4: Impaired expression of GJA5 and SCN5A in IRX5-mutated hiPS-CMs.

A. TaqMan ${ }^{\circledR}$ analysis showing mRNA expression of $S C N 5 A$ and GJA5 in control $(\mathrm{n}=24)$, A150P $(\mathrm{n}=15)$ and N166K $(\mathrm{n}=19)$ IRX5-mutated hiPS-CMs. Cts were normalized to ACTB and each normalized expression value was expressed as compared to the average normalized expression for the control group, generating $2^{-\Delta \Delta \mathrm{Ct}}$ values. A logarithmic scale $(\log 2)$ was used for the $\mathrm{Y}$ axis. * and **: $\mathrm{p}<0.05$ and $\mathrm{p}<0.01$ vs. control, respectively (Mann-Withney test).

B. Representative immunoblots for $\mathrm{Na}_{\mathrm{v}} 1.5$ and $\mathrm{Cx} 40$ and ratios of $\mathrm{Na}_{\mathrm{v}} 1.5$ and $\mathrm{Cx} 40$ expression levels normalized to Transferrin receptor (TFRC). Blots were quantified using Image Lab software. $* *$ and $* * *: \mathrm{p}<0.01$ and $\mathrm{p}<0.001$ vs. control, respectively $(t$ test $)$. Ctrl: $\mathrm{n}=38$; A150P: $n=22 ; N 166 K: n=22$.

C. Representative confocal images for immunostainings of $\mathrm{Na}_{\mathrm{v}} 1.5$ and $\mathrm{Cx} 40$ (green) in Troponin I positive (red) control and IRX5-mutated hiPS-CMs. Nuclei are stained in blue using DAPI.

Figure 5: IRX5 loss-of-function leads to a slower upstroke velocity via reduction of $\mathbf{I}_{\mathrm{Na}}$ 
A. Top panel: representative traces of ventricular APs measured in IRX5-A150P and -N166K mutated and control hiPS-CMs paced at 700ms cycle length with their corresponding first derivatives of the stimulus (S) and of the AP upstroke phases (arrows) of the APs. Dashed lines show the part of the APs on which the derivatives have been calculated. Bottom panel: Box whisker plots of maximum upstroke velocities of ventricular APs when pacing at $700 \mathrm{~ms}$ cycle length without in-silico $\mathrm{I}_{\mathrm{K} 1}$ injection.

B. Resting membrane potentials (RMPs) measured from ventricular APs paced at 700ms cycle length with or without in-silico $\mathrm{I}_{\mathrm{K} 1}$ injection. Mean and SEM are indicated; n: same as in A and $\mathrm{C}$.

C. Top panel: representative traces of ventricular APs measured in A150P and N166K IRX5mutated and control hiPS-CMs paced at 700ms cycle length with their corresponding first derivatives of AP upstroke (arrows). Bottom panel: Box whisker plots of maximum upstroke velocities of ventricular APs when pacing at 700ms cycle length and under dynamic clamp with in-silico $\mathrm{I}_{\mathrm{K} 1}$ injection. $*$ and $* *: \mathrm{p}<0.05$ and $\mathrm{p}<0.01$ vs. control, respectively ( $t$ test).

D. Representative traces of $\mathrm{I}_{\mathrm{Na}}-\mathrm{TTX}$-sensitive and $\mathrm{I}_{\mathrm{Ca}, \mathrm{L}}-\mathrm{Nifedipine-sensitive} \mathrm{in} \mathrm{control} \mathrm{hiPS-}$ CMs, obtained by subtraction of the current recorded before and after application of the inhibitors, when applying typical ventricular-like AP voltages, depicted on top.

E. Superimposed representative traces of $\mathrm{I}_{\mathrm{Na}}$ recorded when applying the depicted voltageclamp protocol, and mean current densities $(\mathrm{pA} / \mathrm{pF}) v s$. membrane potential (EM) recorded in hiPS-CMs. *** and \#\#\# p<0.001 vs. control $(\mathrm{n}=27)$ for respectively IRX5-A150P $(\mathrm{n}=31)$ and -N166K hiPS-CMs (n=30) (Two-way Anova with Bonferroni post hoc test).

F. Superimposed representative traces of $\mathrm{I}_{\mathrm{Ca}, \mathrm{L}}$ recorded when applying the depicted voltageclamp protocol, and mean current densities $(\mathrm{pA} / \mathrm{pF})$ vs. membrane potential $(\mathrm{EM})$ obtained in hiPS-CMs (Ctrl: n=15; A150P: n=14; N166K: n=23).

\section{Figure 6: IRX5 interacts with $S C N 5 A$ and $G J A 5$ promoters.}

A. Schematic representation of potential binding sites for IRX5 (BS, in green; numbers indicate position referring to TSS) on SCN5A promoter identified in-silico, and PCR amplification using primers specific for each BS after hiPS-CMs chromatin immunoprecipitation (ChIP) with an antibody against IRX5. Results are shown as ratio of the immunoprecipitated (IPed) DNA relative to intergenic region (IR). TSS: transcription starting site; CP: core promoter. \#: $\mathrm{p}<0.05$ vs. IR in control samples $(\mathrm{n}=8)$; ***: $\mathrm{p}<0.001$ vs. control in IRX5-mutated samples; A150P $\mathrm{n}=5$ and N166K: $\mathrm{n}=7$ ( $t$ test).

B. IRX5 interaction with GJA5 promoter obtained as in A Ctrl: $\mathrm{n}=6$; A150P: $\mathrm{n}=5 ; \mathrm{N} 166 \mathrm{~K}: \mathrm{n}=7$. 
C. Dissociation constant $(\mathrm{Kd})$ between IRX5 protein and SCN5A promoter obtained after microscale thermophoresis (MST) test using constant concentration of IRX5 protein and decreasing concentration of SCN5A promoter plasmids (from $650 \mathrm{nM}$ to $0.0099 \mathrm{nM}$ ). Two different plasmids containing parts of SCN5A promoter were used: BS2- Plasmid, from -261 to $+613 \mathrm{bp}$, that did not contain IRX5 BS2, and BS2+ Plasmid, from -261 to $+1072 \mathrm{bp}$, which contained IRX5 BS2. Left panel, fitted curves issued using law of mass action. Right panel, histograms showing mean and SEM Kd ( $n=3$ per group, from 3 separated preparations).

D. Luciferase experiments in HEK293 cells cotransfected with BS2+ Plasmid, containing luciferase cDNA under the control of SCN5A promoter region (from $-261 \mathrm{bp}$ to $+1072 \mathrm{bp}$ ), and with expressing vectors encoding wild-type (WT), A150P or N166K-mutated IRX5 cDNA. Firefly luciferase activity was normalized to Renilla activity (mean \pm SEM, $n=3$ per group, from 3 separated preparations) and is shown as ratio vs. condition without IRX5 plasmid.

\section{Figure 7: IRX5 and GATA4 cooperate to regulate $S C N 5 A$ expression.}

A. GATA transcripts expression ratios vs. GATA5 (GATA TF with the lowest expression). Transcript expression ratios were calculated using GTEx data for human ventricular tissues and using TLDA analysis for control hiPS-CMs. Data are expressed as mean \pm SEM.

B. Representative western blots of IRX5 and GATA4 in control and IRX5-A150P mutated hiPS-CM lysates immunoprecipitated with anti-IRX5 antibody. Quantification of the amount of GATA4 co-immunoprecipitated with IRX5, in control and, IRX5-A150P and N166K mutated hiPS-CMs. Results are shown as ratios of the co-immunoprecipitated (IPed) GATA4 normalized to the IPed IRX5 amounts (Ctrl: n=20; A150P: n=11; N166K: n=8).

C. Schematic representation of IRX5 binding site (BS; green) and GATA4 BS (pink) on SCN5A promoter (numbers indicate position referring to TSS), and PCR amplification using primers specific for each BS after hiPS-CMs ChIP with an antibody against IRX5. Results are shown as ratio of the IPed DNA relative to intergenic region (IR). TSS: transcription starting site. \#: $\mathrm{p}<0.05$ vs. intergenic region ( $t$ test). Ctrl: $\mathrm{n}=7$; A150P $\mathrm{n}=4$ and N166K: $\mathrm{n}=6$.

D. Luciferase experiments in HEK293 cells cotransfected with BS2- plasmid, containing luciferase cDNA under the control of SCN5A promoter region $(-261 \mathrm{bp}$ to $+613 \mathrm{bp})$ with GATA4 BSb but not IRX5 BS2 (white bars), or BS2+ plasmid, containing luciferase cDNA under the control of SCN5A promoter region $(-261 \mathrm{bp}$ to $+1072 \mathrm{bp})$ with GATA4 BSb and IRX5 BS2 (green bars), and with the indicated GATA4 or/and IRX5 expressing plasmids. Firefly luciferase activity was normalized to Renilla and is shown as ratio to its activity when 
CVR-2019-1019R2

transfected with SCN5A plasmids only. Results are displayed for 3 independent cell preparation and transfection. $* * * *: p<0.0001 v s$. condition with no IRX5/GATA4 plasmid; \#\#\# and \#\#\#: $\mathrm{p}<0.001$ and $\mathrm{p}<0.0001$ vs. condition with GATA4 plasmid only; $\$ \$ \$: \mathrm{p}<0.001$ $v s$. condition with GATA4 + WT-IRX5 plasmids $(t$ test $)$. 
Figure 1

A. Murine tissues Human tissues
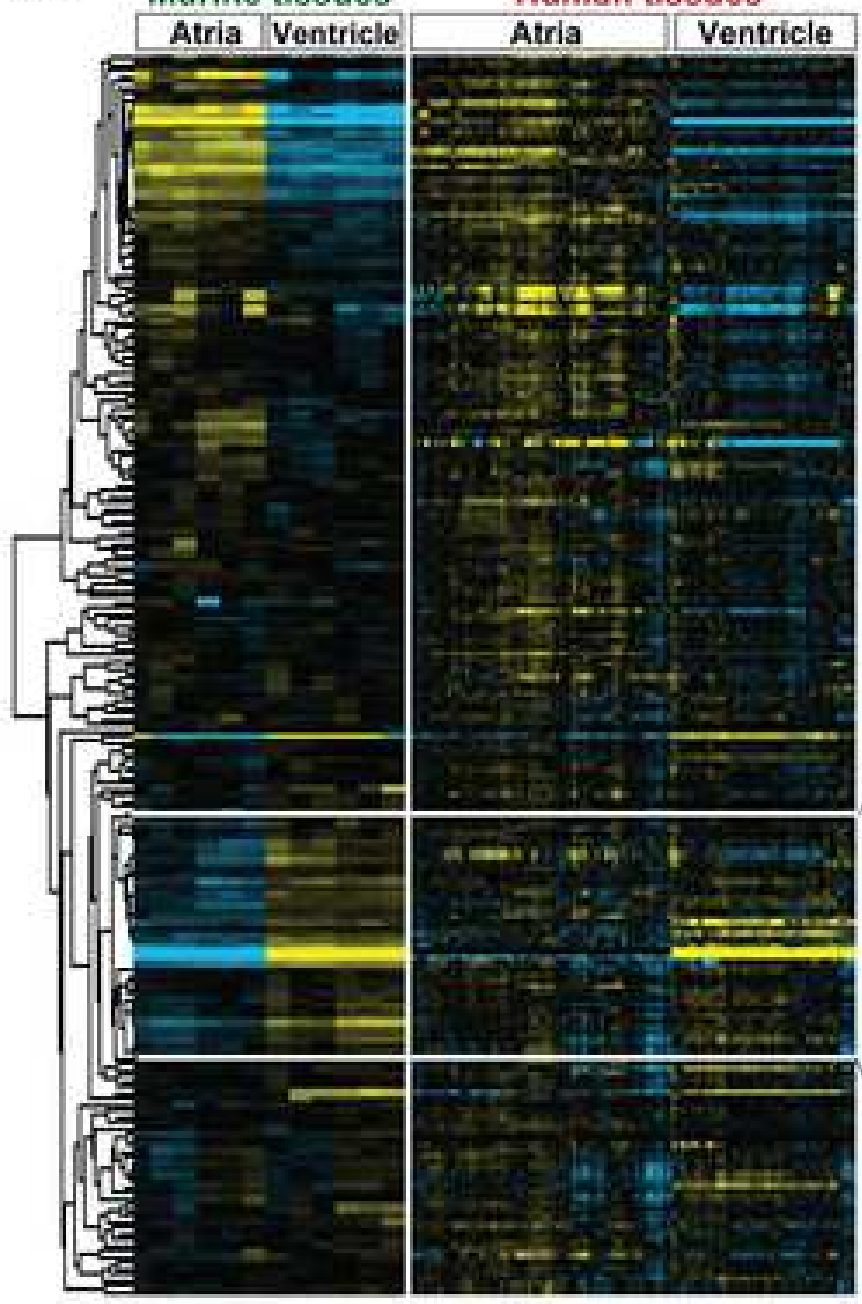

B.

Log2(TPM) Human left ventricle tissues

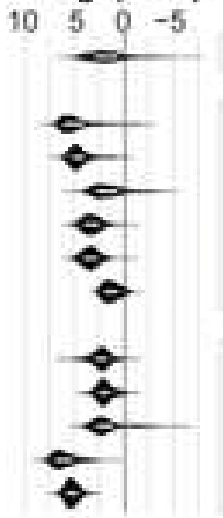

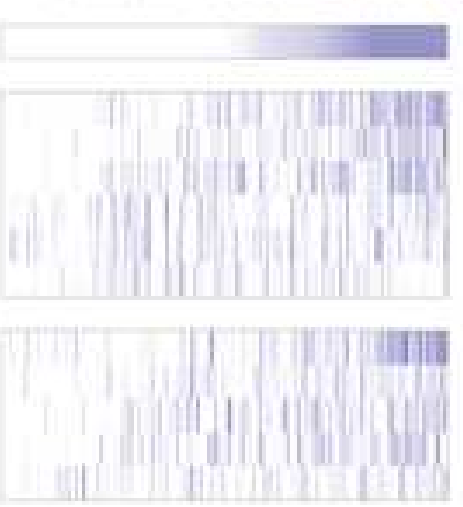

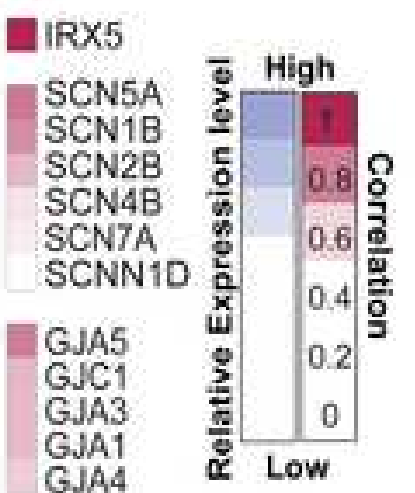

C.
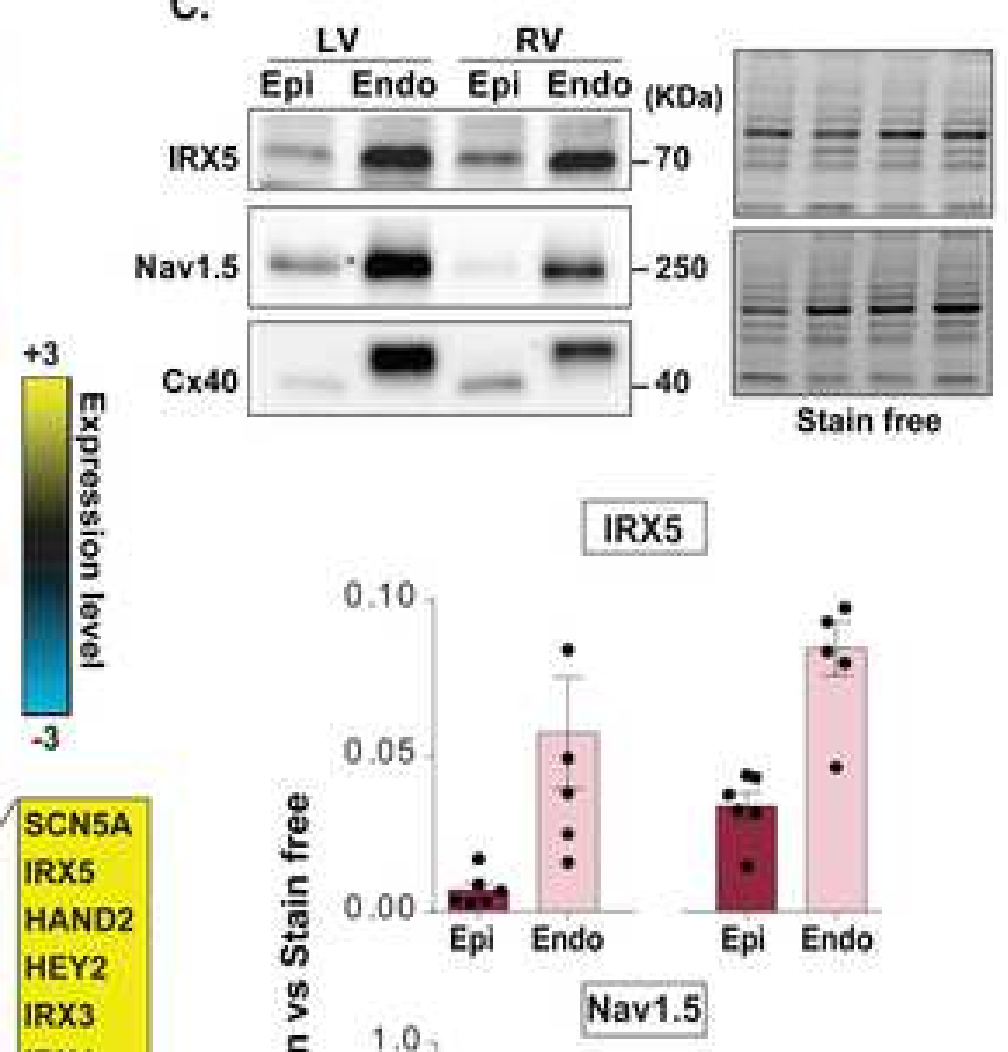

KCNIP2

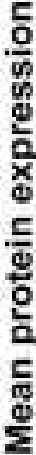

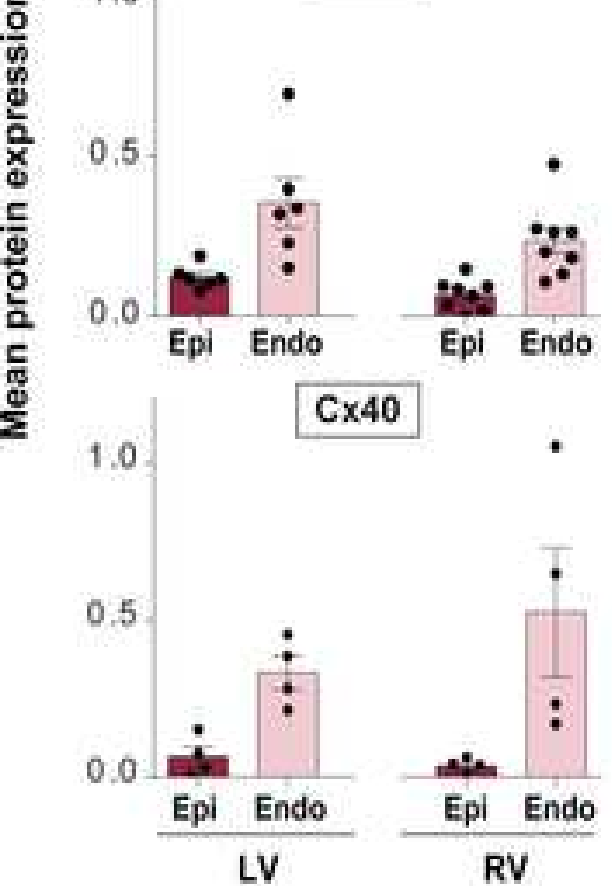


Figure 2

A.
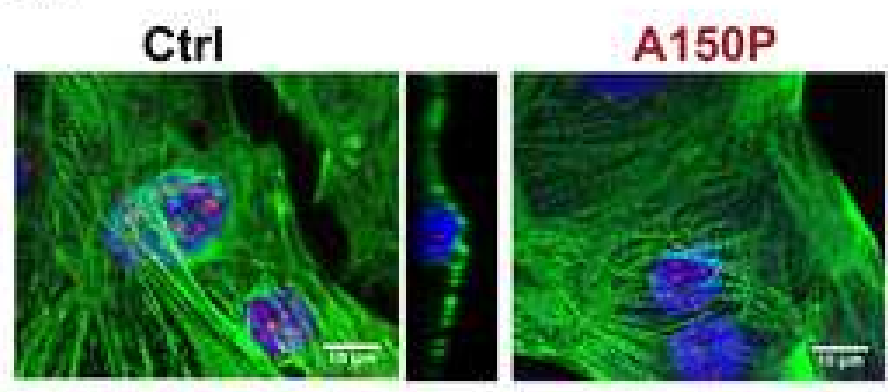

c.

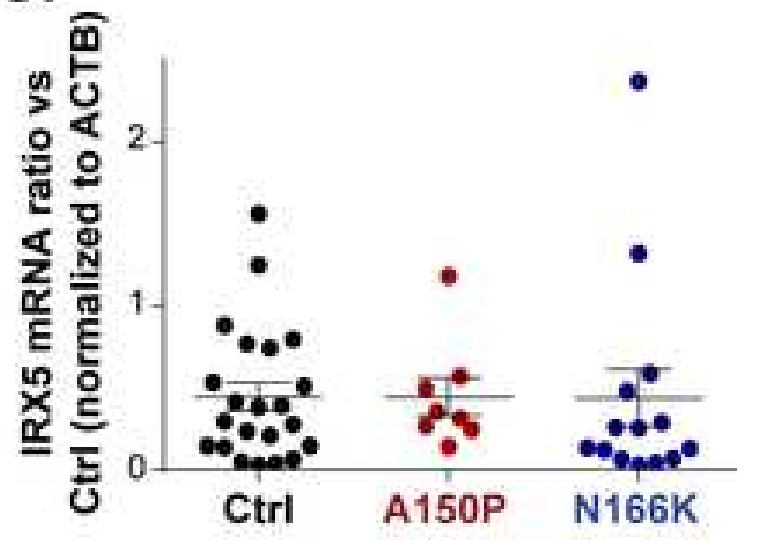

D.

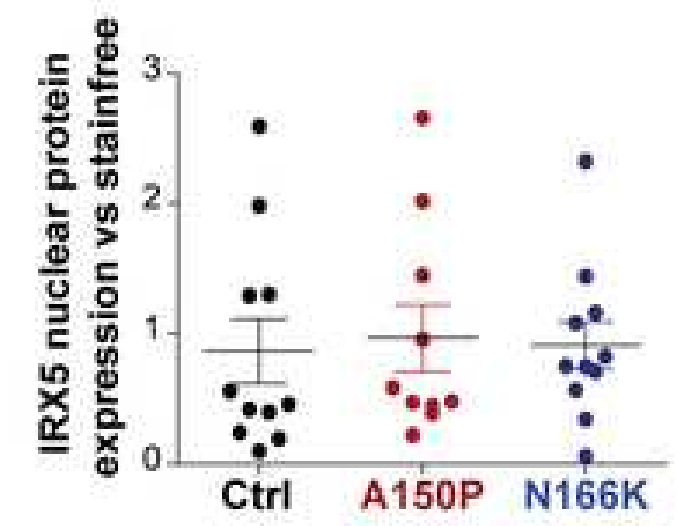

B.

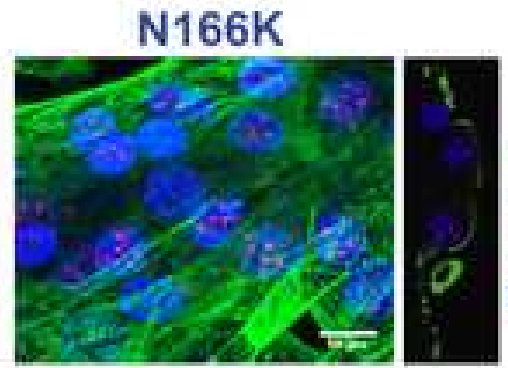

Troponin | IRX5 DAPI
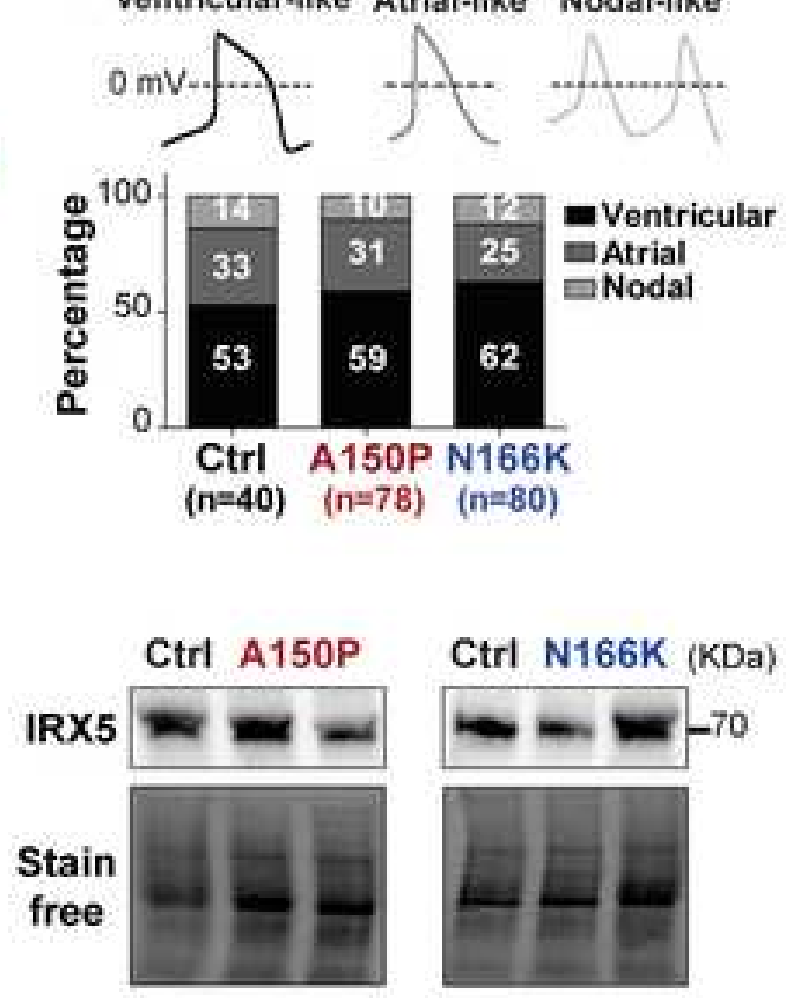


\section{Figure 2}

A.
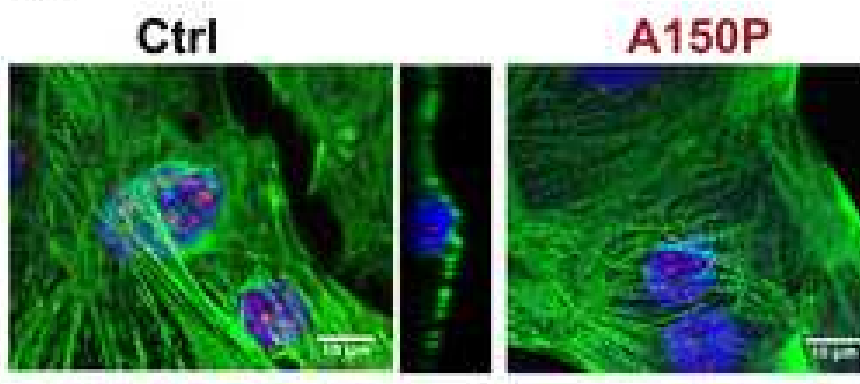

C.

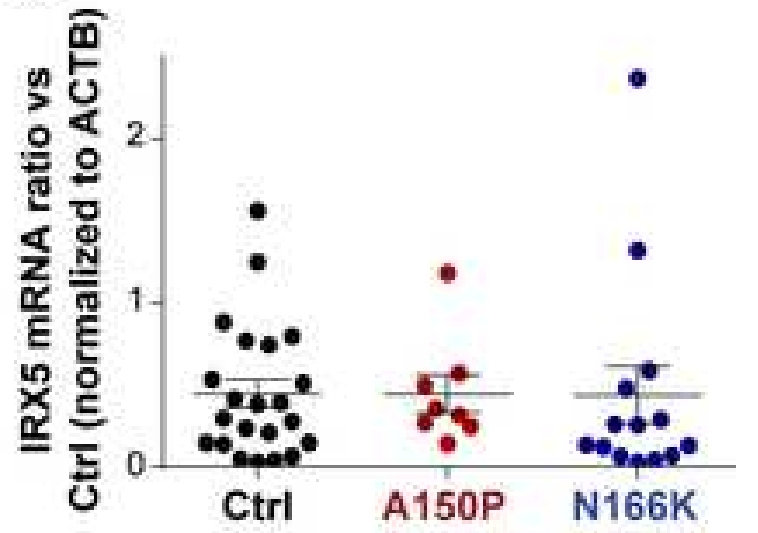

D.

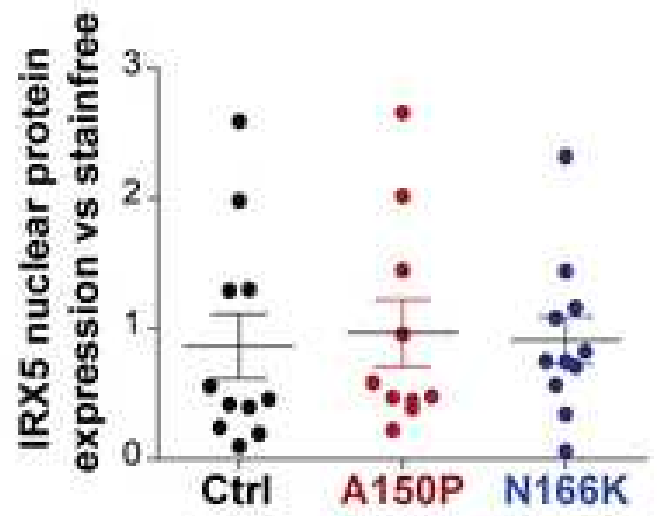

B.

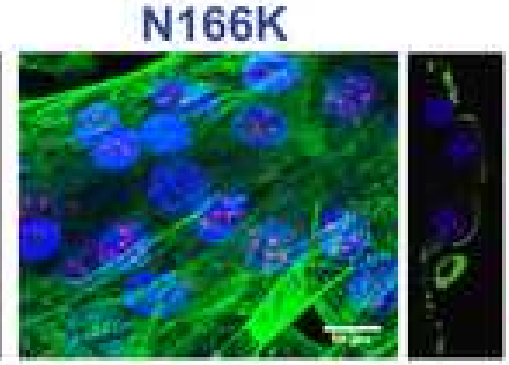

Troponin IRX5 DAPI
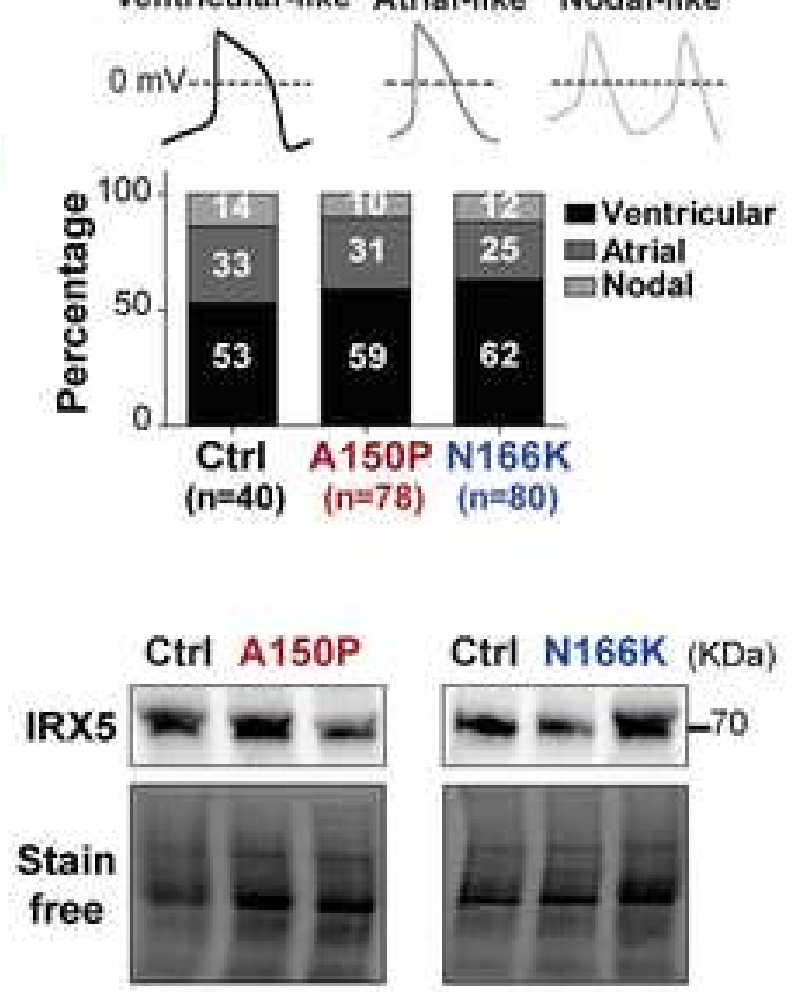
Figure 3

A.

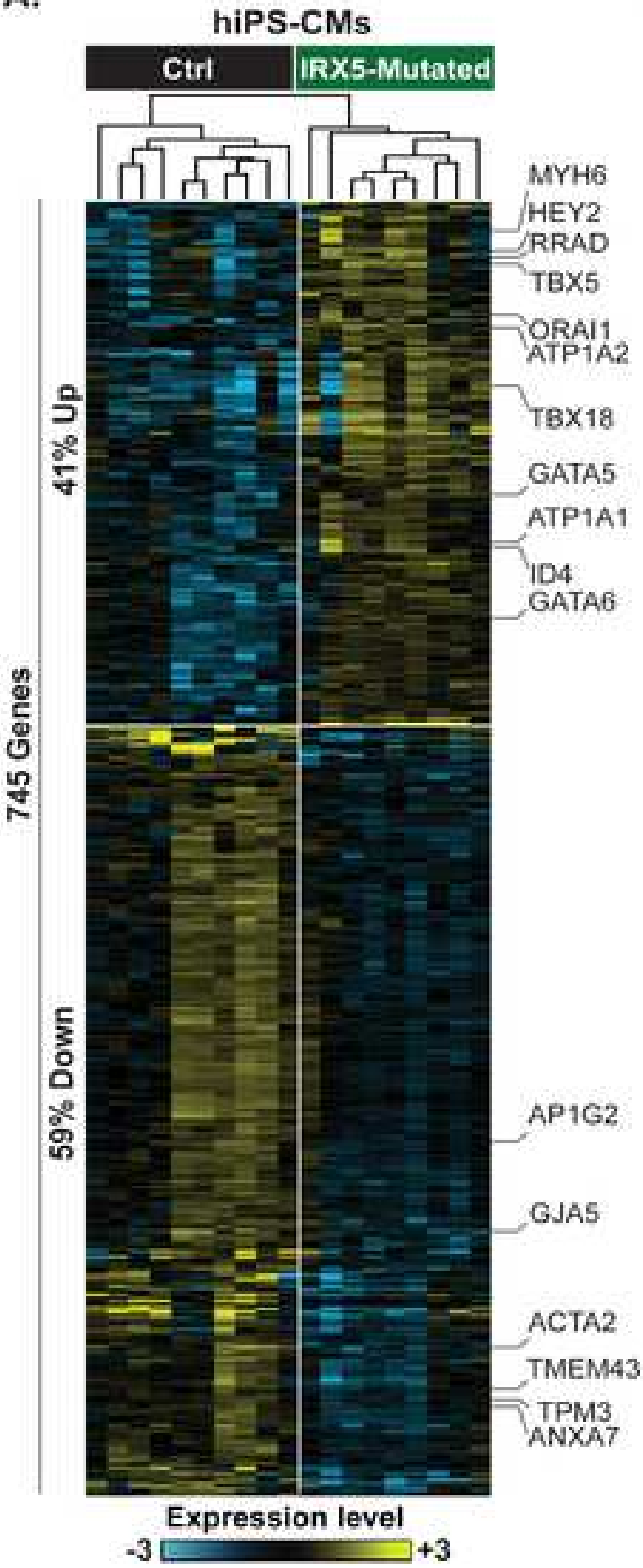

B.

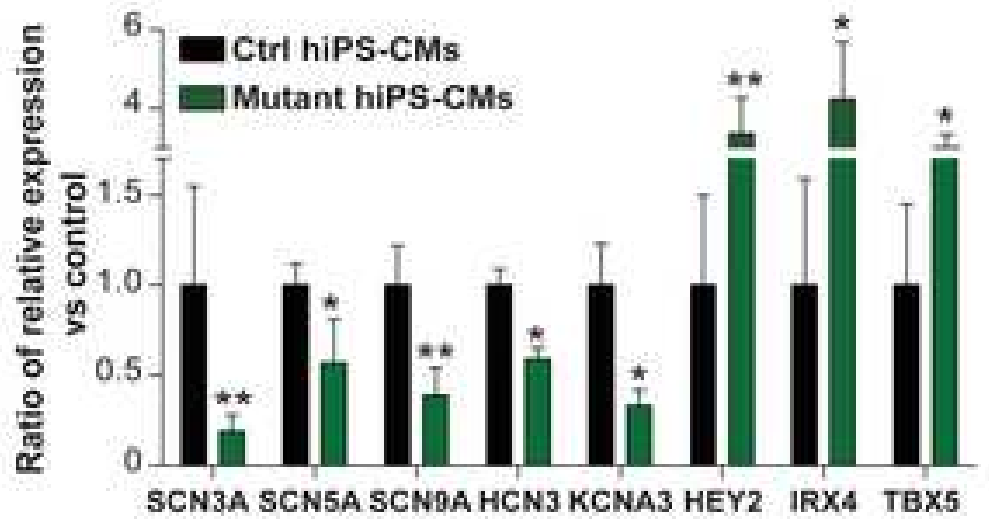

C.

Programmed cell death

DNA replication

Celt death

Metabolism of proteins Metabolism of RNA

Response to external stimuli Muscle contraction Developmental biology

Signal transduction

Extracellular matrix organization

Transport of small molecules

Disease Immune system
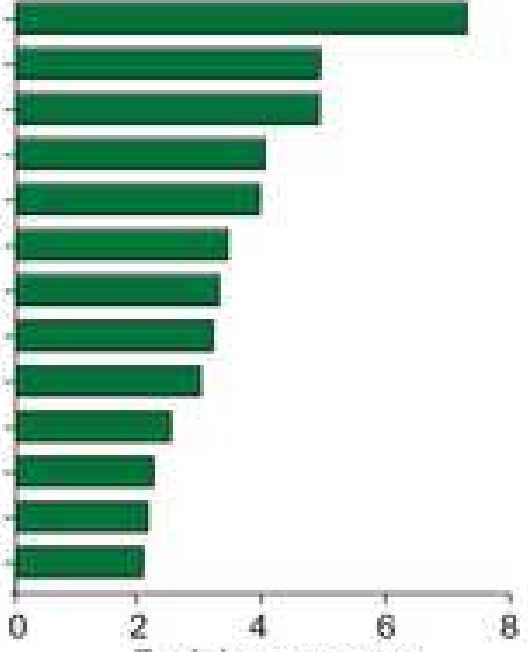

Enrichment score

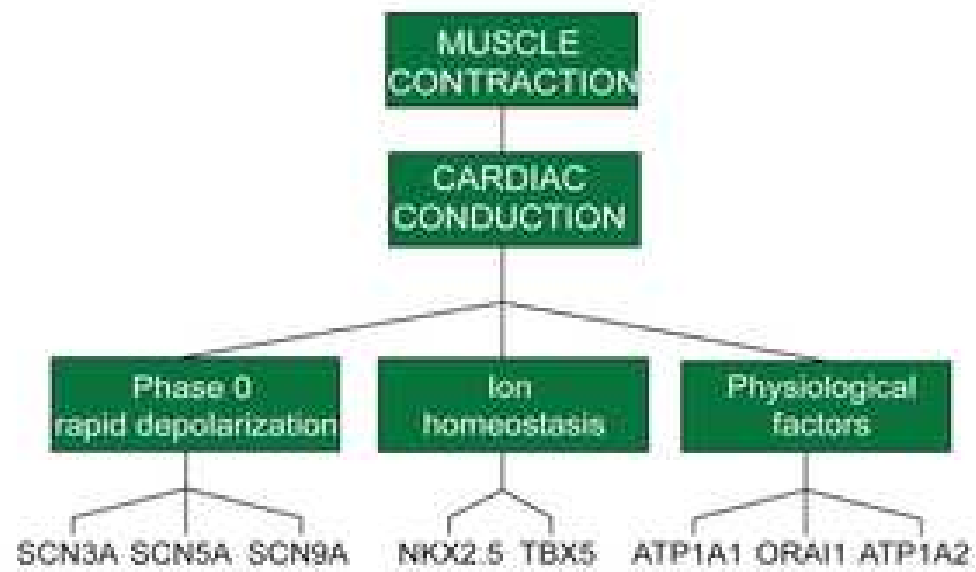


Figure 4
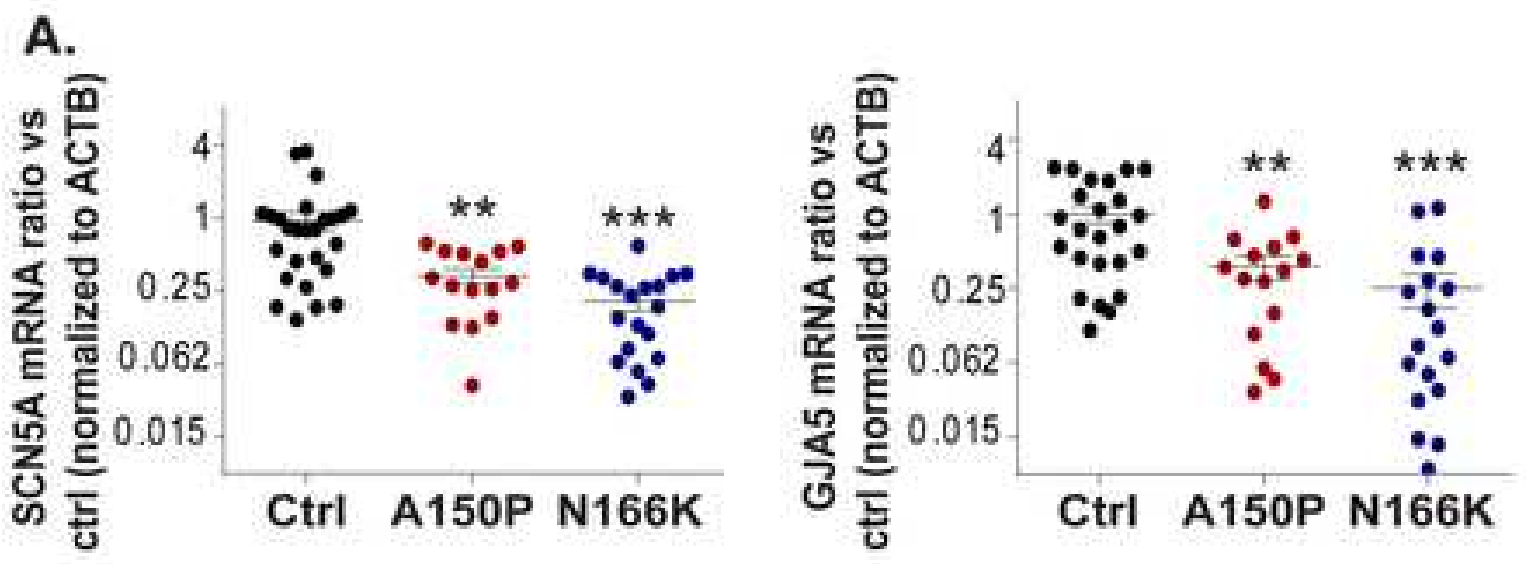

B.
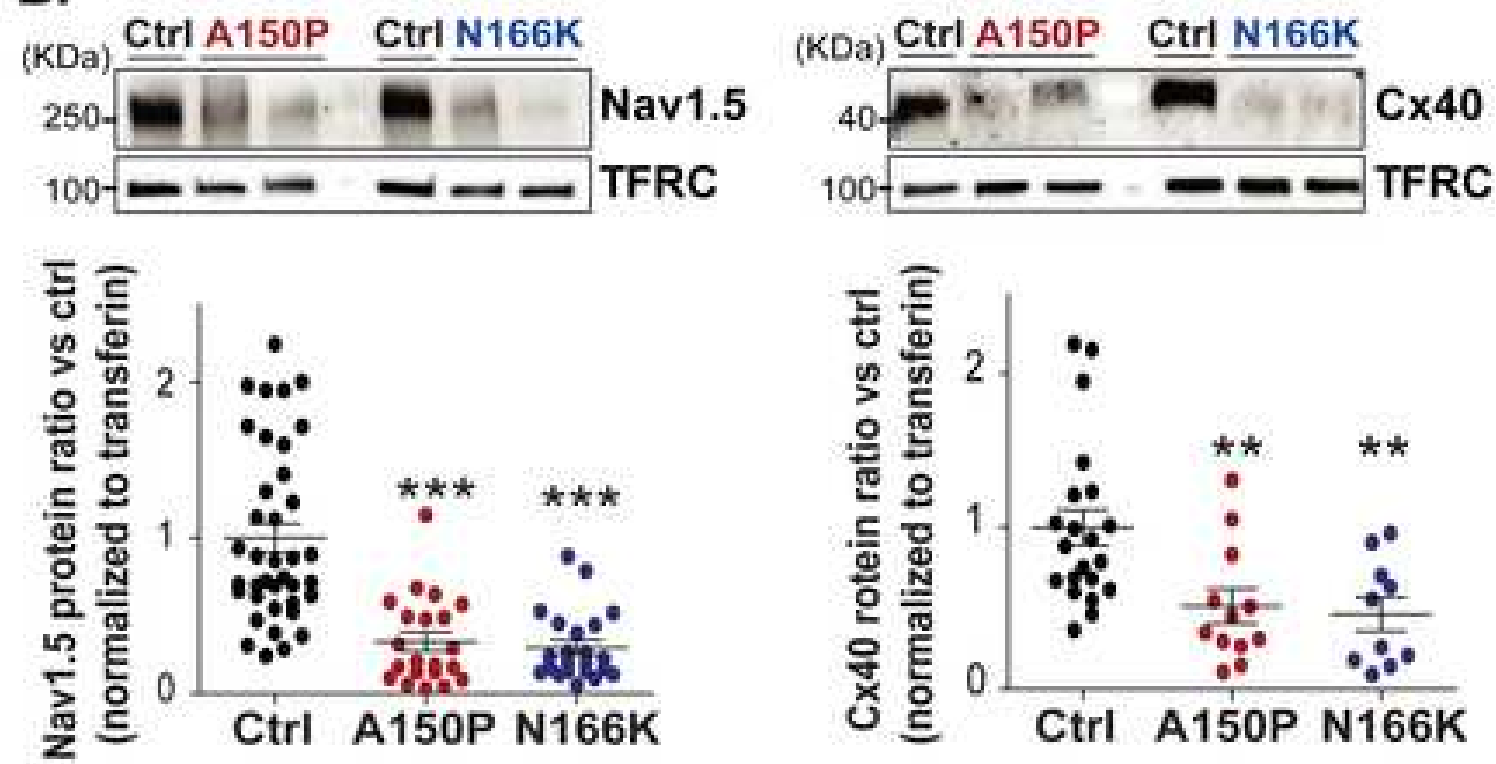

c.
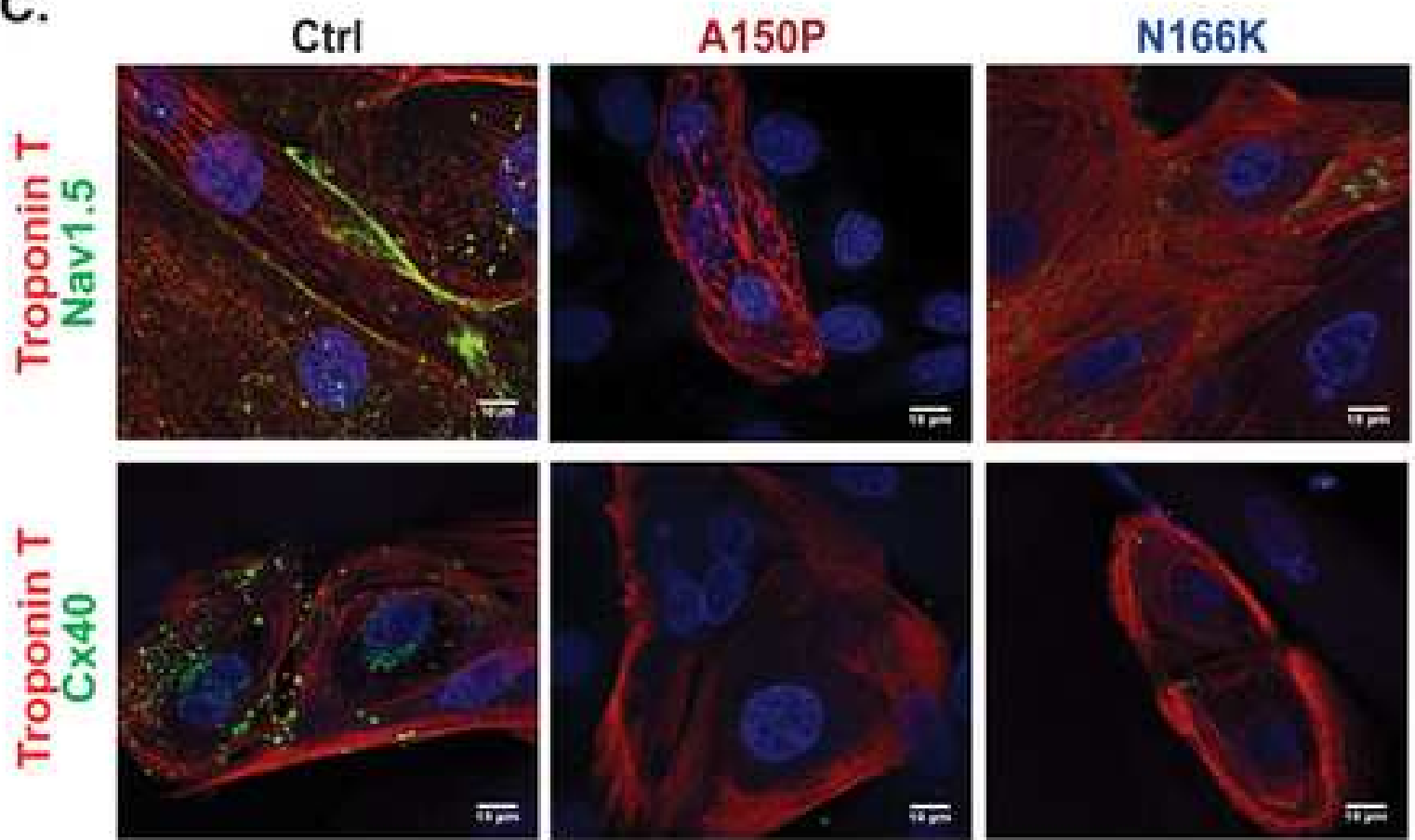
Figure 5

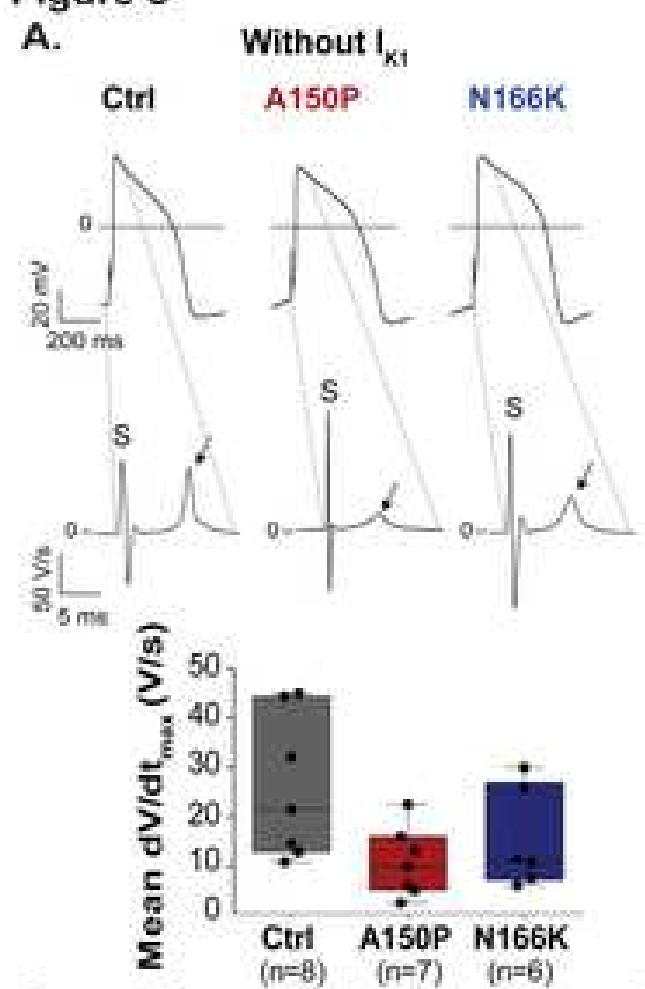

D.

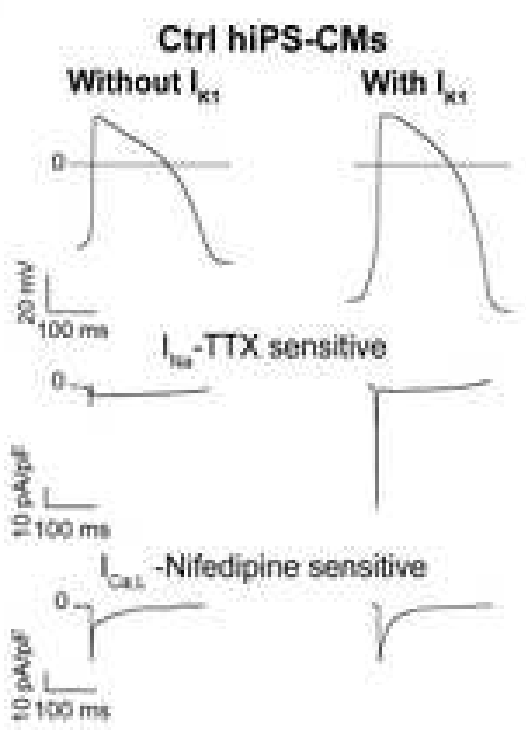

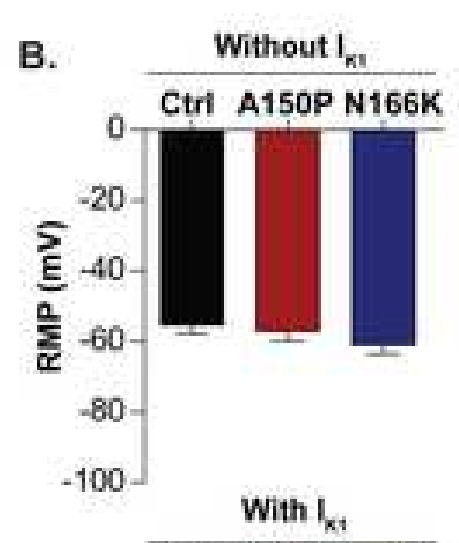

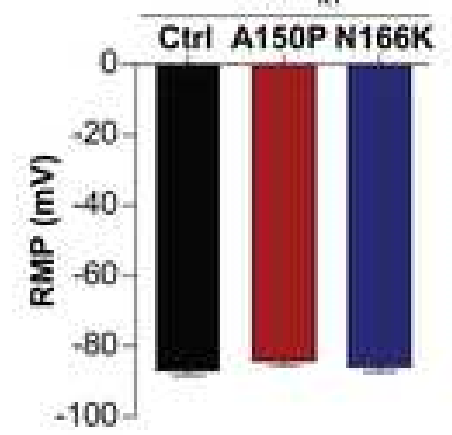

E.
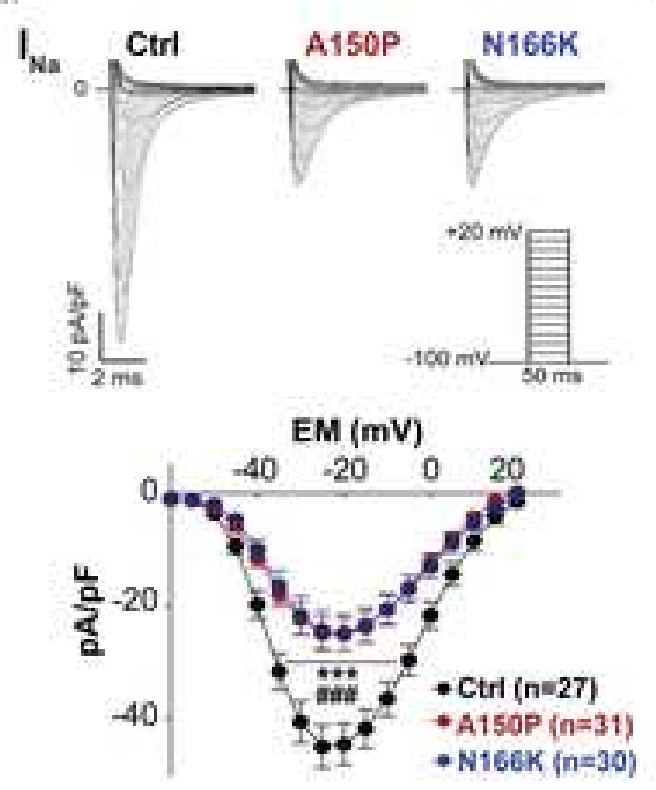

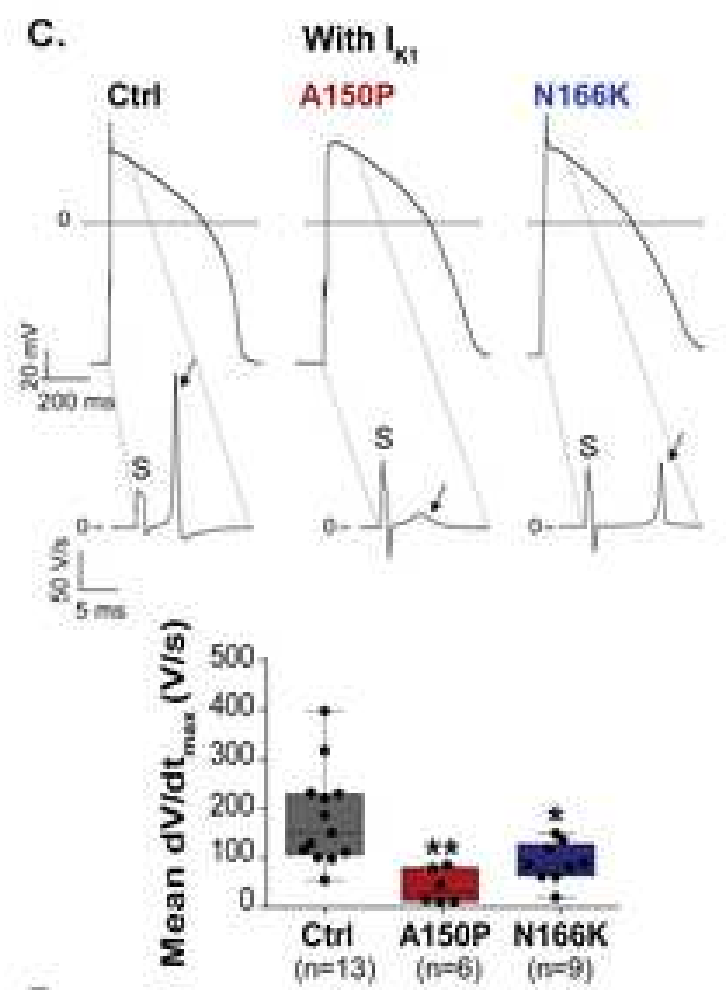

F.
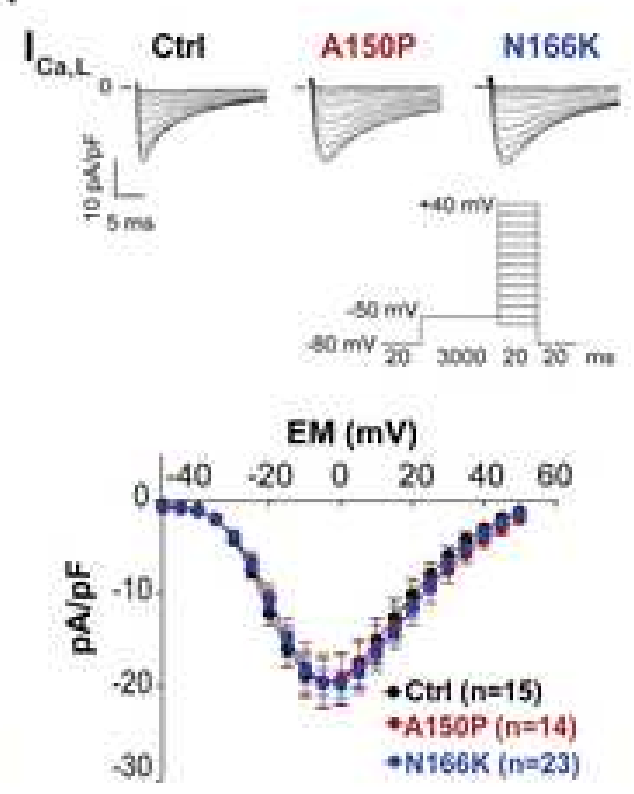
Figure 6

A.
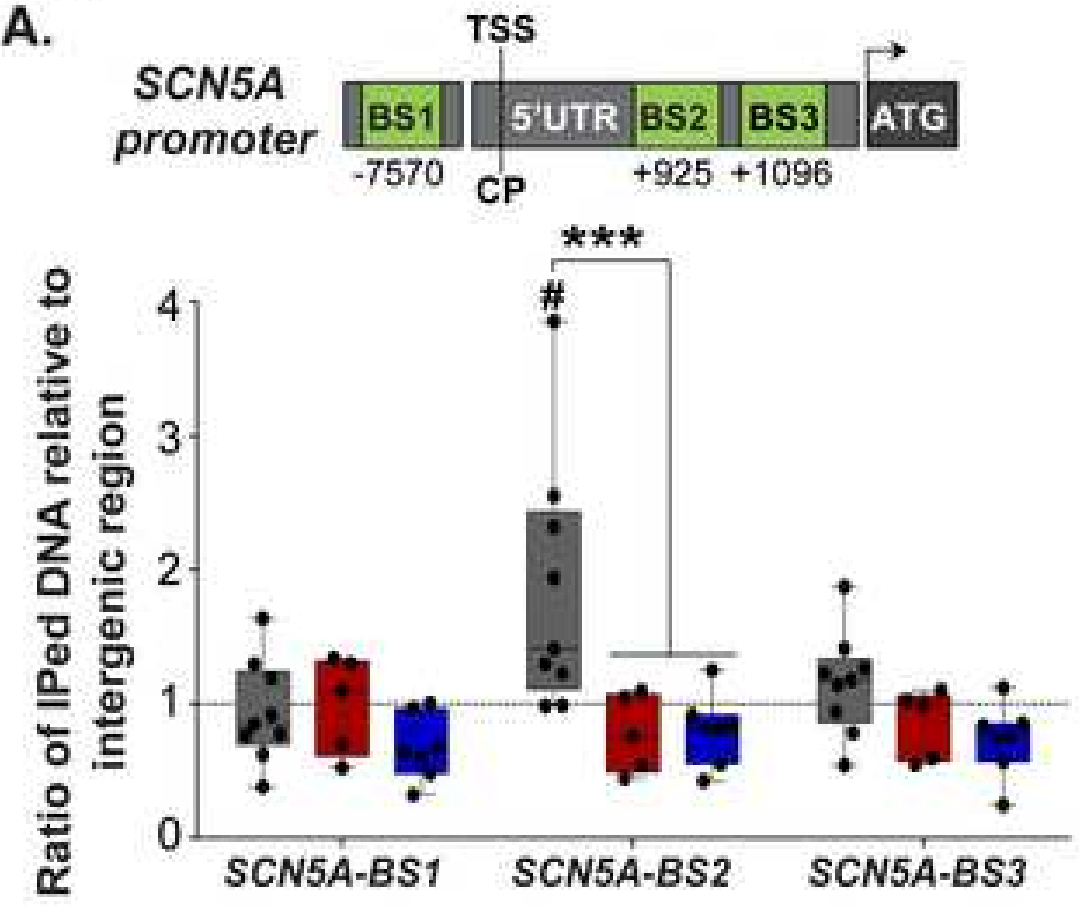

c.

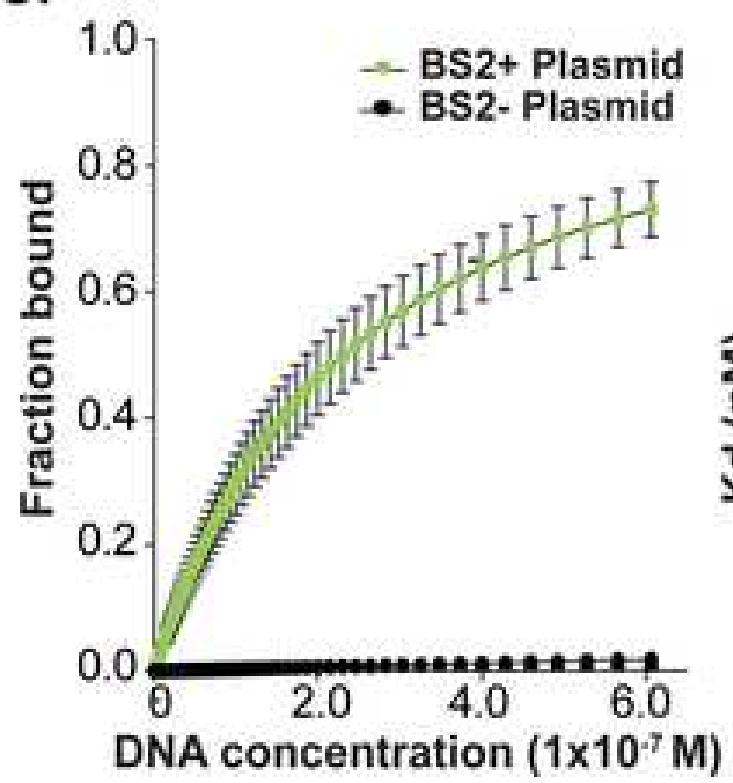

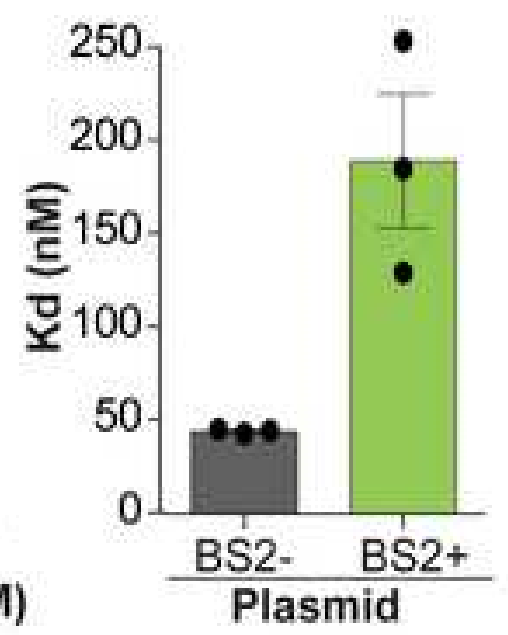

B.
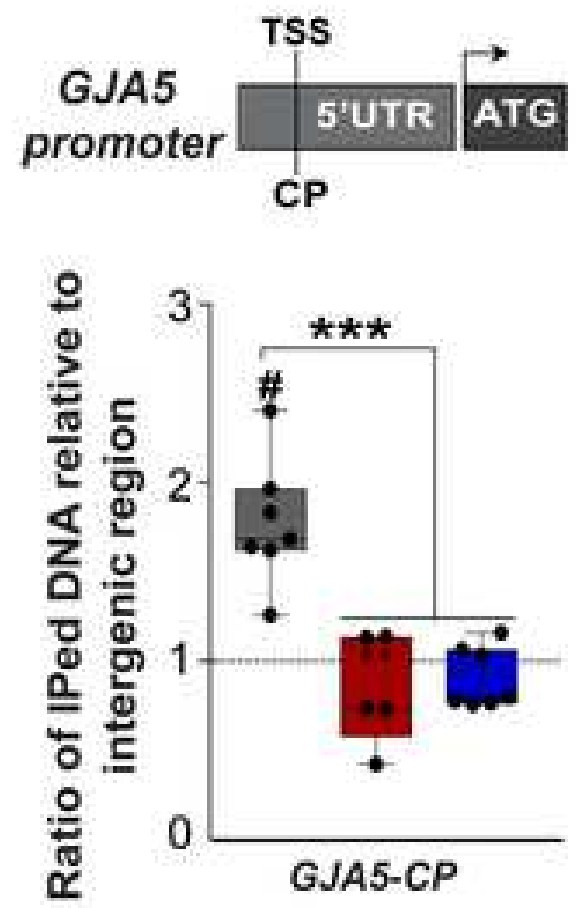

D.
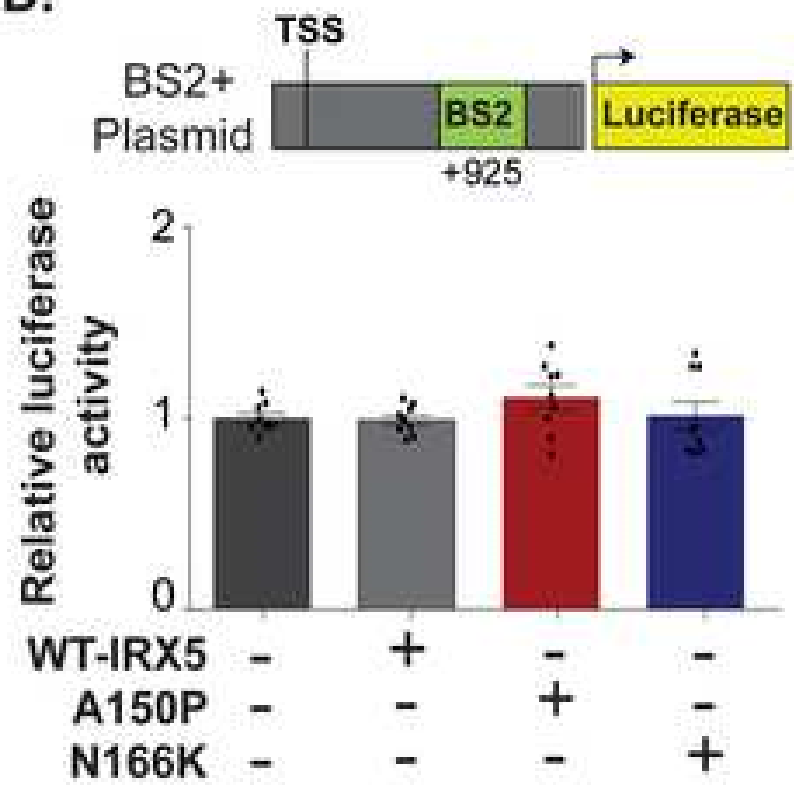
Figure 7

A.

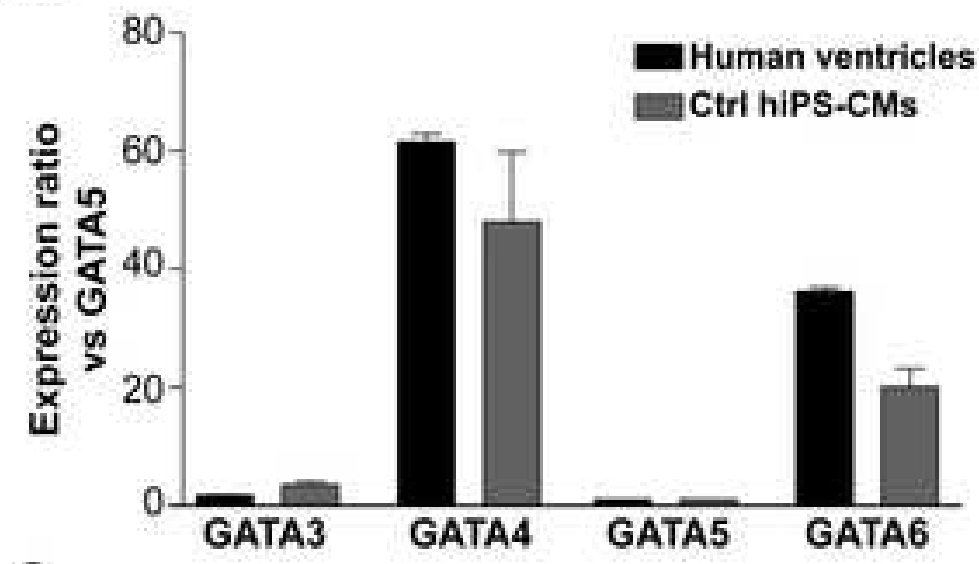

c.
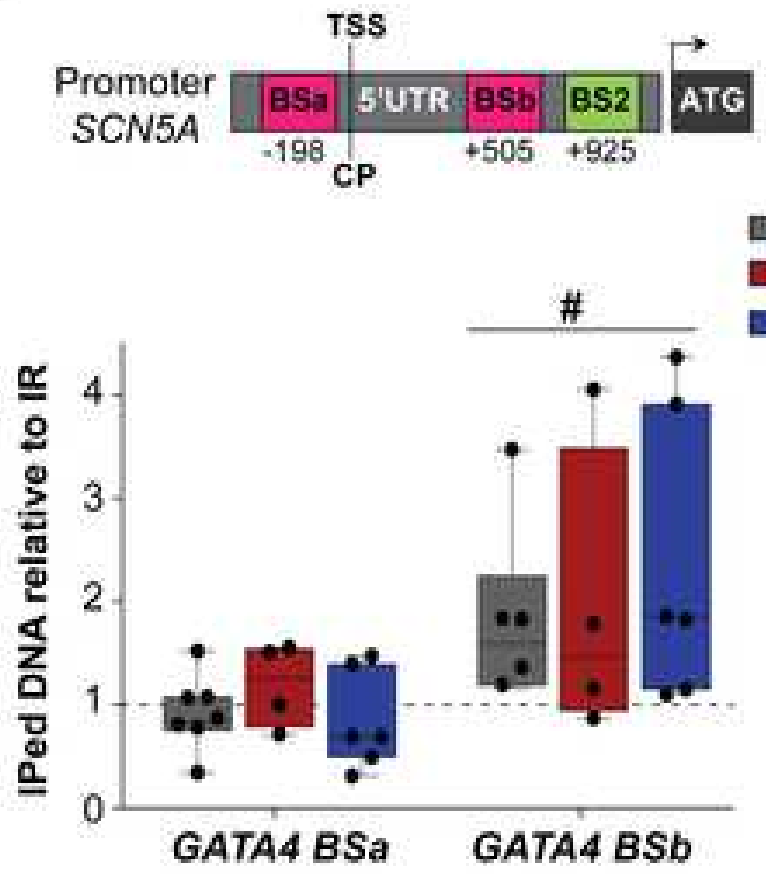

B.
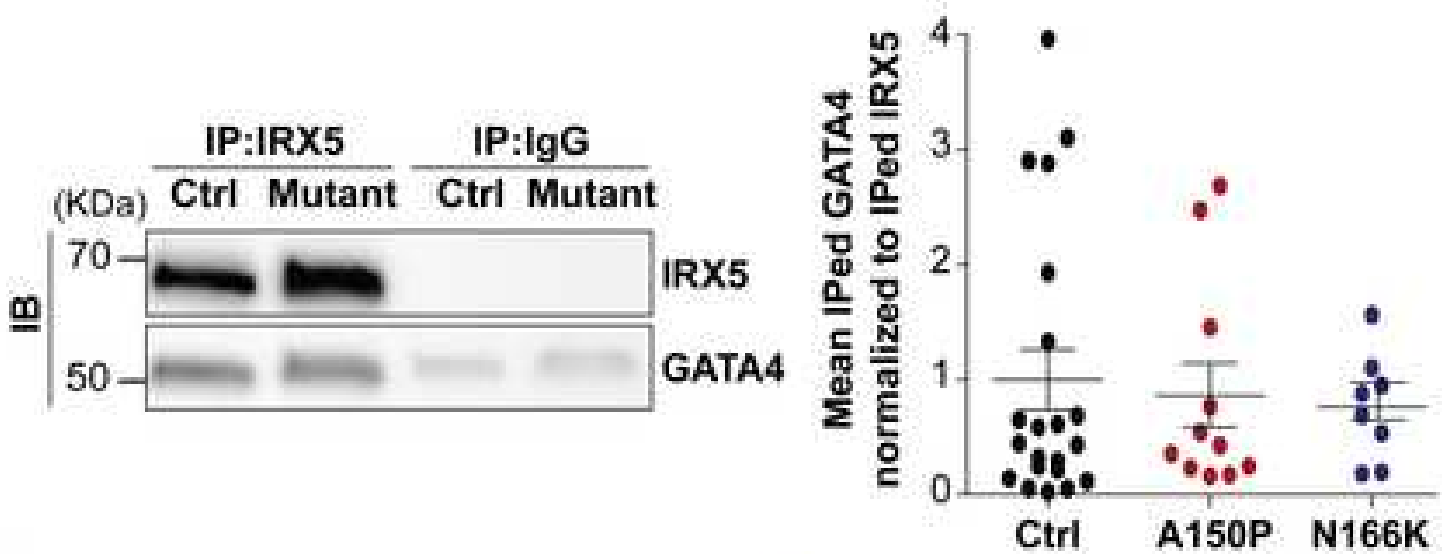

D.

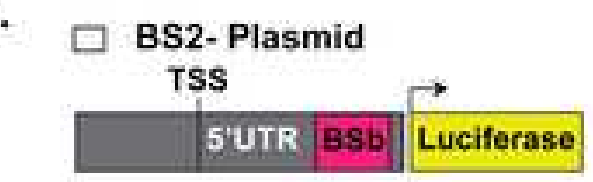

aS2+ Plasmid
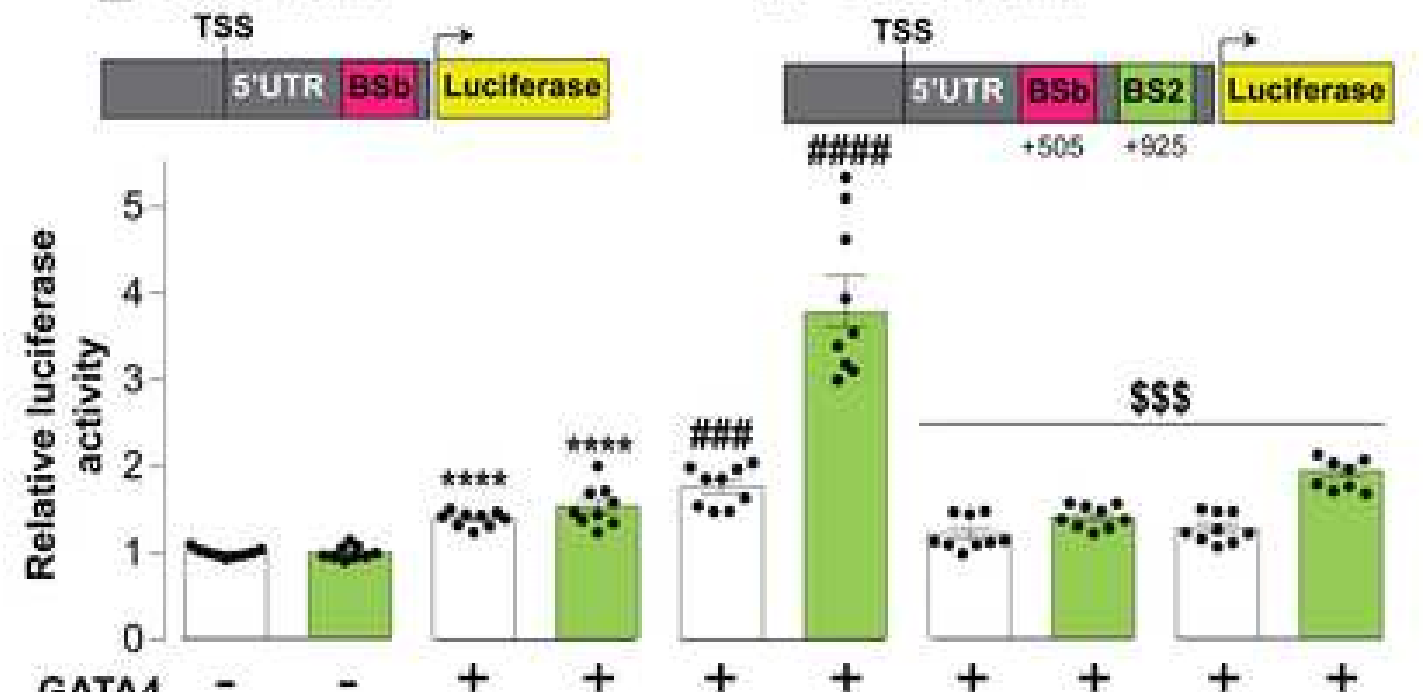

$$
\begin{array}{r}
\text { GATA4 - } \\
\text { WT-IRX5 - } \\
\text { A150P - } \\
\text { N166K - }
\end{array}
$$$$
-++
$$

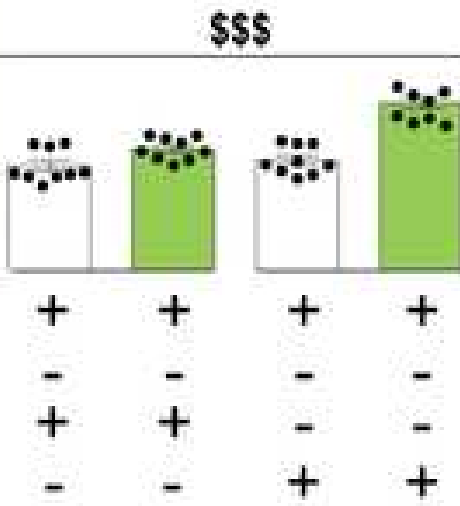




\section{Transcriptional regulators}

Functional

IRX5

GATA4

SCN5A

GJA5

Conduction velocity
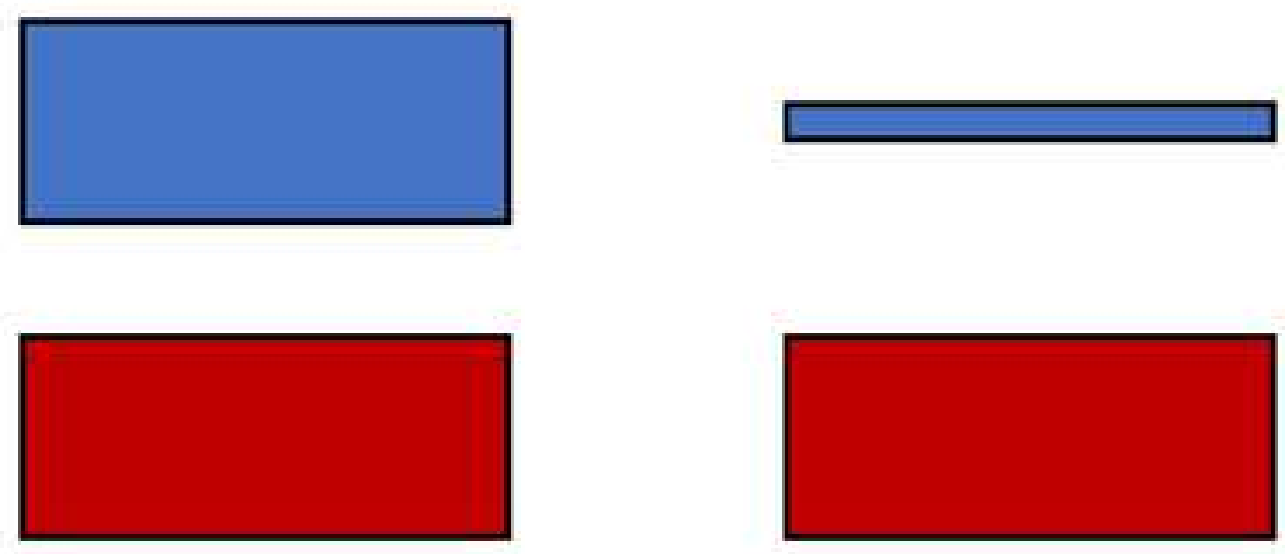

Impact on target gene expression
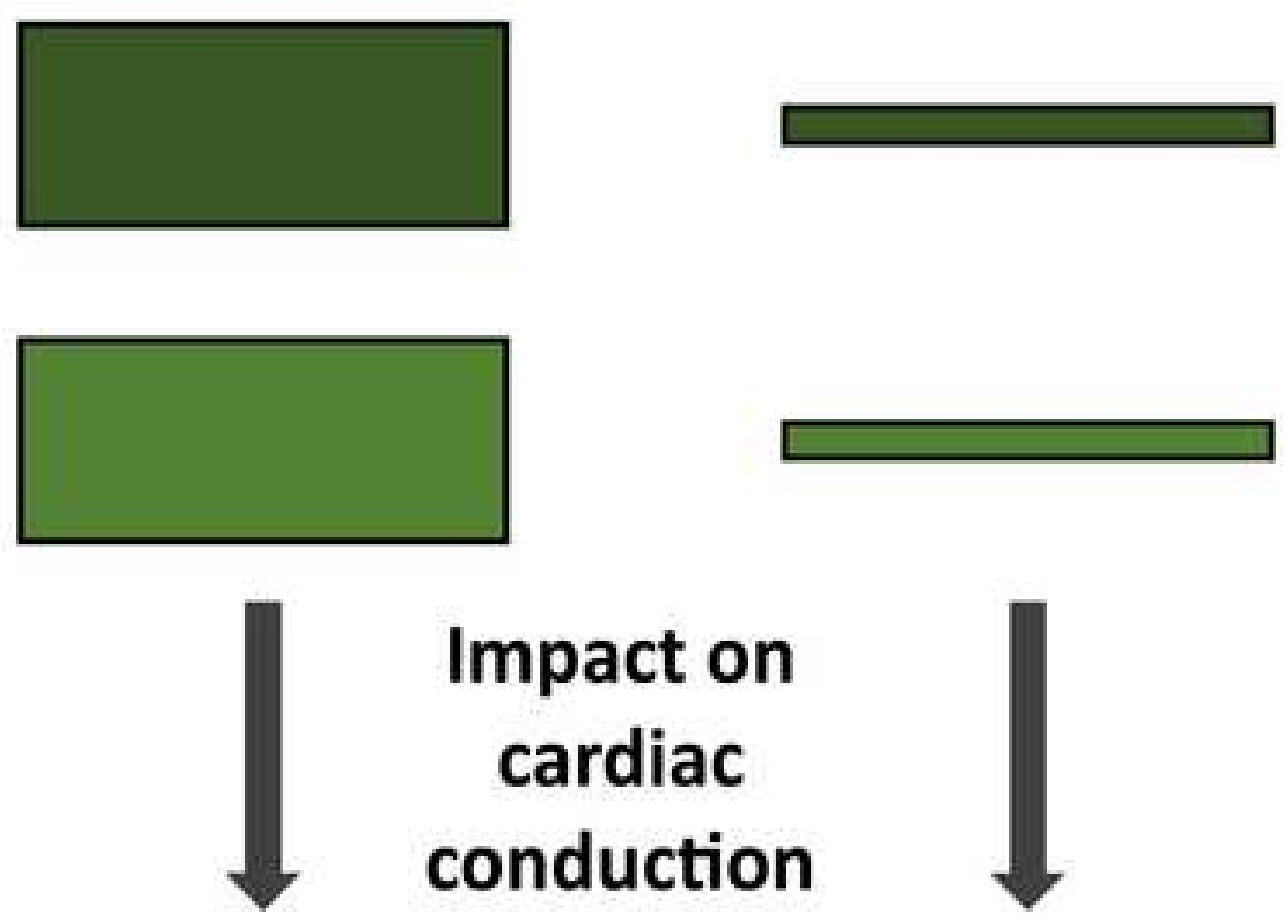

Faster 